\title{
An assessment of the taxonomic validity of three species of marsupial frogs (Anura: Hemiphractidae: Gastrotheca) from the Yungas of Bolivia based on external morphology and cranial osteology
}

\author{
CLAUDIA LANSAC ${ }^{1}$, RODRIGO AGUAYO ${ }^{2} \&$ IGNACIO DE LA RIVA ${ }^{1, *}$ \\ ${ }^{1}$ Department of Biodiversity and Evolutionary Biology, Museo Nacional de Ciencias Naturales-CSIC, C/ José Gutiérrez Abascal, \\ Madrid 28006, Spain. ”clau.lansac@hotmail.es; 느ttps://orcid/org/0000-0002-6082-1252 \\ ${ }^{2}$ Centro de Biodiversidad y Genética, Universidad Mayor de San Simón, Casilla 538, Cochabamba, Bolivia. \\ "="phrynopus@gmail.com; $\odot$ https://orcid.org/0000-0001-9842-6218 \\ "Corresponding author."iriva@mncn.csic.es; (1) https://orcid.org/0000-0001-5064-4507
}

\begin{abstract}
The genus Gastrotheca (Anura: Hemiphractidae) is a group of marsupial frogs particularly diverse in Andean regions. Several taxonomic studies of this genus have been conducted in the humid cloud forests — or Yungas —of the Andean eastern slopes of central Bolivia (departments of Cochabamba and Santa Cruz). Yet, the distinction among three species that occur sympatrically in these forests, G. lauzuricae (proposed as a junior synonym of G. coeruleomaculatus in 2015), G. piperata, and G. splendens, remains unclear since the morphological characters that purportedly support their differentiation are variable and partly shared among them. We have carried out external morphological studies, including multivariate morphometric analyses, to assess how they support the taxonomic status of these three species. We also evaluated characters of the cranial osteology of a sample of six individuals using micro CT-scanning. Principal component and linear discriminant analyses resulted in a great overlap among the putative species. Cranial osteological comparisons did not reveal highly significant differences among them, but suggested that different degrees of hyperossification could be related to the developmental state of individuals. Our results indicate that most morphological and osteological reported differences between the three species likely represent intraspecific variation. Thus, we propose that the three nominal species belong to a single biological entity, for which the name Gastrotheca splendens (Schmidt, 1857) has priority. We also restrict the name Gastrotheca coeruleomaculatus (Werner, 1899) to externally similar congeneric populations from the Yungas forests of department of La Paz, but highlighting the need of a detailed evaluation of their taxonomic identity.
\end{abstract}

Key words: Amphibia, cranial osteology, co-ossification, dorsal coloration, hyperossification, morphology, taxonomy

\section{Resumen}

El género Gastrotheca (Anura: Hemiphractidae) es un grupo de ranas marsupiales altamente diverso, especialmente en las regiones andinas. Varios estudios taxonómicos de este género se han llevado a cabo en los bosques húmedos montañosos - o Yungas - de la vertiente oriental de los Andes del centro de Bolivia (departamentos de Cochabamba y Santa Cruz). La distinción entre tres especies que se encuentran en simpatría en estos bosques, G. lauzuricae (propuesta como sinónimo posterior de G. coeruleomaculatus), G. piperata y G. splendens, no está clara, ya que los caracteres morfológicos que supuestamente apoyan su diferenciación son variables y están parcialmente compartidos entre ellas. Mediante estudios de morfología externa —incluyendo análisis morfométricos multivariantes — evaluamos la validez taxonómica de estas tres especies. Además, examinamos la osteología craneal de una muestra de seis individuos con microtomografía computarizada. Los análisis de componentes principales y discriminante lineal mostraron un gran solapamiento entre las supuestas especies, y las comparaciones osteológicas no revelaron diferencias sustanciales entre ellas, pero sí sugieren que los diferentes grados de hiperosificación podrían estar relacionados con el estado de desarrollo de los individuos. Nuestros resultados indican que la mayoría de las diferencias morfológicas y osteológicas descritas para las tres especies probablemente representan variación intraespecífica, por lo que proponemos la existencia de una única entidad biológica, para la que el nombre Gastrotheca splendens (Schmidt, 1857) tiene prioridad. Se establece que el nombre aplicable a las poblaciones similares de Gastrotheca de los Yungas del departamento de La Paz sería Gastrotheca coeruleomaculatus (Werner, 1899), pendiente de posteriores estudios taxonómicos. 
Palabras clave: Amphibia, coloración dorsal, co-osificación, hiperosificación, morfología, osteología craneal, taxonomía

\section{Introduction}

Marsupial frogs of the genus Gastrotheca Fitzinger (Anura: Hemiphractidae) are characterized by carrying fertilized eggs in a pouch on the back of the female, open posteriorly. Some species are direct-developers while others have aquatic larvae, and all species for which developmental observations are available present embryos with unique bell-shaped gills (del Pino \& Escobar 1981). Most of the 76 described species of Gastrotheca (Frost 2021) are restricted to South America (two species reach Middle America), mainly occurring in the Andean regions, from lowland and montane humid rainforests to high-elevation Andean grasslands; ten species occur in eastern Brazil (Duellman 2015; Frost 2021). Several phylogenetic analyses have explored the relationships of Gastrotheca, both intrageneric and with other genera of Hemiphractidae (Wiens et al. 2007; Blackburn \& Duellman 2013; Duellman et al. 2014; Duellman 2015; Castroviejo-Fisher et al. 2015; Echevarría et al. 2021). These works found the genus to be monophyletic, showing a good concordance between geography and lineages. Specifically, Blackburn \& Duellman (2013) found most Andean species (representing the greatest diversity in the genus) to form a monophyletic group subdivided into two lineages; one of them, the so-called central Andean clade, include the species occurring at high elevations in the Andes of southern Ecuador, Peru, Bolivia, and lower elevations in the Andes of northwestern Argentina. Another study based on twenty genes and 51 phenotypic characters (Castroviejo-Fisher et al. 2015) confirmed again the monophyly of Gastrotheca and recognized 68 species arranged in four different groups (fissipes, longipes, marsupiata, and microdiscus), which are not totally coincident in species composition with those of previous studies. The most recent work recognizes those four species groups plus the G. walkeri Group (Echevarría et al. 2021).

From the early 1990s, exhaustive inventories revealed the great diversity of anurans in the humid cloud forests_-or "Yungas" _ of the Andean eastern slopes of Bolivia (De la Riva 1990; De la Riva et al. 2000; Köhler 2000), which highlighted the need to undertake further taxonomic studies, particularly on highly diverse genera and on those poorly known in the country, like Gastrotheca. Several works on taxonomy and amphibian diversity including material of Gastrotheca from Bolivia have been conducted (Vellard 1957; Duellman \& Fritts 1972; De la Riva 1992; De la Riva et al. 2000; Köhler 2000) and yet uncertainties remain regarding how many species occur in this country, their morphological characteristics and relationships, and where are they distributed.

A particular species, characterized by its large size and direct development, is Gastrotheca testudinea (Jiménez de la Espada), distributed along the eastern slopes of the Andes of Ecuador, Peru, and Bolivia (Duellman \& Lynch 1988; Duellman 2015), although in Bolivia only a few specimens have been reported in the departments of Cochabamba and La Paz (De la Riva et al. 2000). Köhler (2000) suggested that this wide distribution could hide more than a single species, an idea supported by the non-monophyly of G. testudinea found by Echevarría et al. (2021). However, this topic is beyond the scope of this work, which is focused on the taxonomic problems posed by other, smaller Bolivian forms belonging to the G. marsupiata group. An outline of the taxonomic background of these Bolivian Gastrotheca species follows.

Nototrema bolivianum Steindachner was the first marsupial frog reported in Bolivia, in the department of Cochabamba, followed a few years later by Hylodes coeruleomaculatus Werner in the department of La Paz. Boulenger (1900) placed $H$. coeruleomaculatus under the synonymy of $N$. bolivianum, which was later synonymized with Nototrema marsupiatum (Duméril \& Bibron) by Nieden (1923). Thus, both names were considered by Duellman \& Fritts (1972) as synonyms of Gastrotheca marsupiata, a highly variable species widely distributed in the Peruvian and Bolivian Andean regions at elevations from 2760 to 4230 m (Frost 2021). However, De la Riva (1992) observed that Bolivian populations identified as pertaining to this species occurring below the upper limit of the Andean humid cloud forests $(\sim 2800-3000 \mathrm{~m}$ ) had a remarkable variation compared to those from the highlands (approx. above $3000 \mathrm{~m}$ ), which have a dorsally mottled pattern. In the same work, he described a new species, G. lauzuricae, from the upper limit of the cloud forests of La Siberia (on the border between the departments of Cochabamba and Santa Cruz), occurring in sympatry with other forest populations then considered G. marsupiata; the description was based on a single individual, and the reported main diagnostic characteristics of this new species were the presence of bright blue spots on dorsum and flanks and a different head shape (De la Riva 1992). 
Another species Hyla splendens Schmidt, had been earlier described also from a single specimen (an adult male), purportedly from Bocas del Toro, Panama. Duellman (1977) stated that the holotype of this species was apparently a member of the genus Gastrotheca, and the published type locality could be in error, probably being in the Andes instead of Central America. In concordance with this interpretation, a specimen (MNK 1988, an adult female) collected in 1996 in Abra de la Cruz (department of Santa Cruz, Bolivia), was identified as Gastrotheca splendens since it matched the characteristics of the holotype of Schmidt (1857), especially the skin of the head coossified with the underlying cranial bones. The description of the species was improved and expanded based on this second specimen (Duellman \& De la Riva 1999).

Finally, the remaining cloud forest populations from the Bolivian departments of Cochabamba and Santa Cruz, at elevations of 1850-2800 m, were considered as representatives of an additional species, Gastrotheca piperata Duellman \& Köhler, which could be distinguished from $G$. lauzuricae mainly by lacking blue spots and from $G$. splendens by lacking cranial skin co-ossified with the underlying bones (Duellman \& Köhler, 2005).

In summary, five Gastrotheca species-G. lauzuricae, G. marsupiata, G. piperata, G. splendens, and G. testudinea-were considered in subsequent updates of Bolivian amphibian checklists (e.g., Aguayo 2009; De la Riva \& Reichle 2014). Because of their apparent rarity, G. lauzuricae and G. splendens were considered endangered (De la Riva \& Aguayo 2009a, b). In their taxonomic revision of Hemiphractidae, Castroviejo-Fisher et al. (2015) and Echevarría et al. (2021) included these five species in the G. marsupiata species group, although they stated that phenotypic characters supporting the distinction among some of them have to be revised. In particular, both studies recovered a monophyletic group with short branches and polytomies including G. marsupiata and Argentinean and Bolivian species, further casting doubts about the validity of some of these species and the need to perform a systematic revision. Slightly discrepant with such taxonomic arrangements for Bolivian Gastrotheca was Duellman (2015), who resurrected, G. coeruleomaculatus (misspelled therein as G. caeruleomaculatus) and placed G. lauzuricae under its synonymy, thus modifying his previous criterion of considering G. coeruleomaculatus a synonym of G. marsupiata (Duellman \& Fritts 1972). Both decisions are problematic. Duellman (2015) justified partially the resurrection of G. coeruleomaculatus upon morphometric differences between the holotype of G. marsupiata (an adult female) and one of the two syntypes of G. coeruleomaculatus, a subadult male. However, this comparison is unappropriated due to the large instraspecific and sexual variation in morphometric characters within G. marsupiata, as demonstrated by Duellman (2015: Table 12.11). The second argument relies on the original description provided by Werner (1899), who stated that both syntypes of $G$. coeruleomaculatus have bright blue flecks, a character only apparent in live specimens, and absent from specimens of G. marsupiata. Duellman (2015) based his conclusion regarding the synonymy of $G$. coeruleomaculatus and G. lauzuricae on a single shared character taken from the original descriptions: the presence of blue spots in live specimens (Fig 1A). Furthermore, Duellman (2015: Appendix 2) assigned nine and three preserved specimens from the departments of Cochabamba and Santa Cruz, respectively, to G. coeruleomaculatus without further discussion. This decision seems arbitrary according to his own argument in which the presence of blue flecks (only observable in live specimens) is the only diagnostic character.

Despite all these recent studies, the taxonomic situation of Gastrotheca coeruleomaculatus, G. lauzuricae, G. piperata, and G. splendens remains surrounded by uncertainty. Based on the aforementioned taxonomic discrepancies, it seems that a revision of this genus in Bolivia needs to be conducted for a better understanding of its diversity, especially the small forms from cloud forests, as claimed by Castroviejo-Fisher et al. (2015).

Skeletal structures in vertebrates have been in general considered to be relatively stable over evolutionary time, and thus have been traditionally used for the classification of taxa of high categories (e.g. Trueb 1970). Also, at a lower taxonomic level, the diversity of character states in skeletal structures such as the skull can in many cases throw light on taxonomic problems. For instance, some species of Gastrotheca exhibit broadly expanded casqued skulls (Trueb \& Duellman 1978), while others have extensive exostosis (deposition of additional membrane bone on the skeleton to form ridges, crests, and reticulate or pitting pattern on the surface of bones), or co-ossification of the dermal roofing bones with the overlying skin (Trueb 1973). All these features are caused by hyper-ossificationincreased mineralization - that might be associated with reduction of evaporative water loss in arid microhabitats (Trueb 1970; Seibert et al. 1974), and with reinforcement of the skull in species that capture large prey as well as in species that present phragmotic behavior (Trueb 1970; Jared et al. 2005). Additionally, recent investigations demonstrate that hyper-ossification has evolved independently more than 25 times throughout the evolutionary history of frogs, and many distantly-related hyper-ossified lineages have converged on similar extreme skull shapes, which may be associated to specific functions or behaviors (Blotto et al. 2021; Paluh et al. 2020). Within 
Gastrotheca, G. splendens is the only Bolivian species known to present cranial co-ossification, specifically with maxillae, nasals, frontoparietals and anterior rami of squamosals (Duellman \& De la Riva 1999).

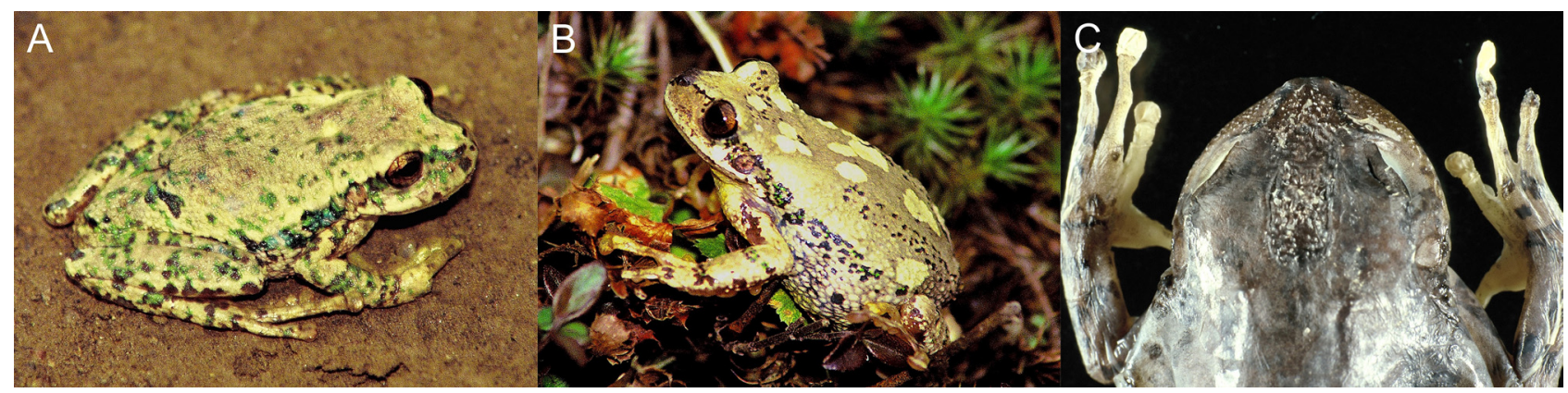

FIGURE 1. Three nominal species of Gastrotheca from the Yungas of central Bolivia: (A) G. lauzuricae: female holotype, EBD 37379H, 34.3 mm SVL, from La Siberia, 2800 m, province Carrasco, Cochabamba, Bolivia; (B) G. piperata: female EBD 37243H, 41.9 mm SVL, from Yunga de Mairana, 2300 m, province Florida, Santa Cruz, Bolivia; (C) G. splendens: female MNK 1988, 44.7 mm SVL, from Abra de la Cruz, province Caballero, Santa Cruz, Bolivia. Photos by I. De la Riva. Note the variation on the dorsal coloration pattern (A, B) and the cranial co-ossification externally visible (C).

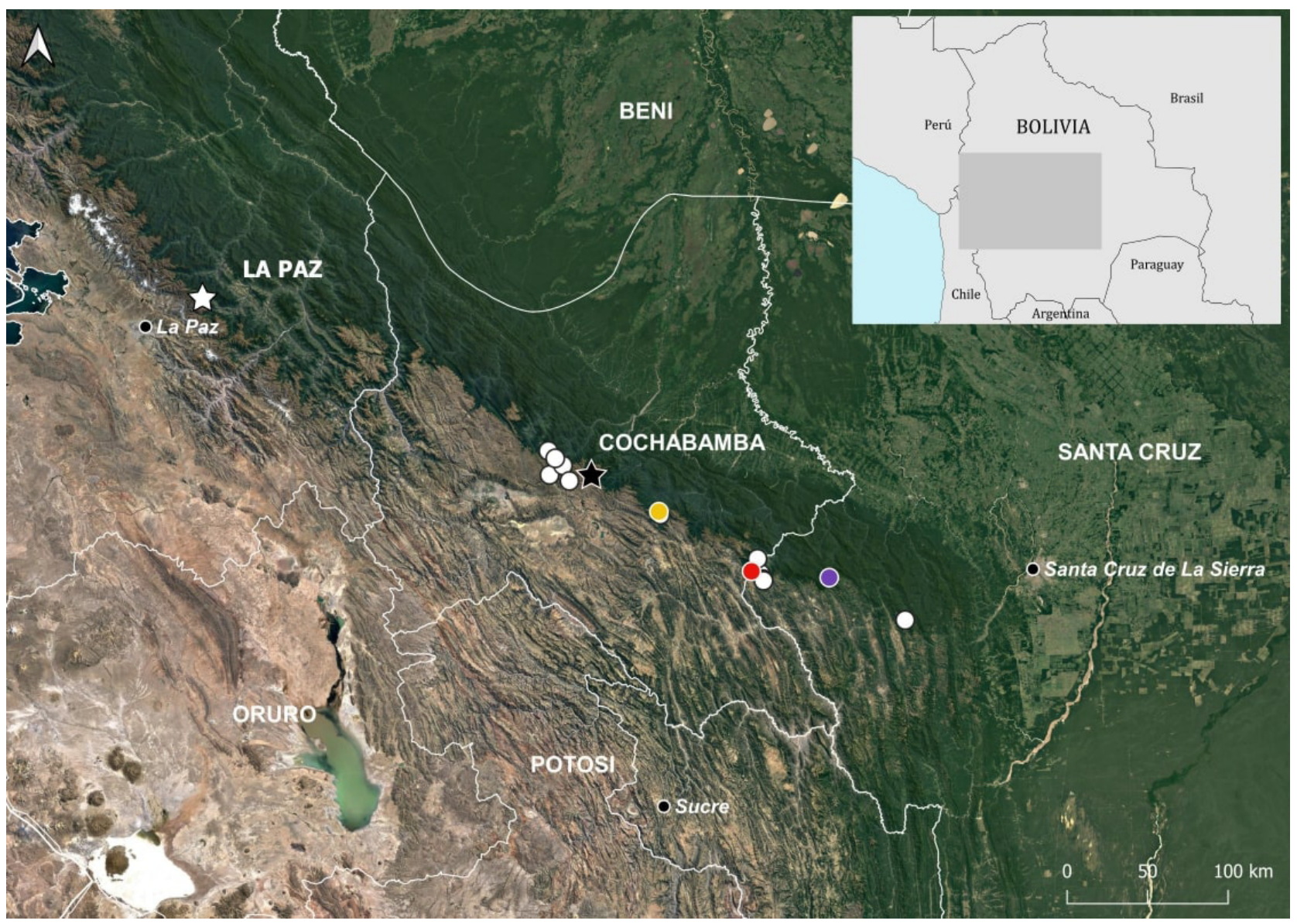

FIGURE 2. Localities of Gastrotheca from the cloud forests (Yungas) of Bolivia. Red dot: type locality of G. lauzuricae; yellow dot: type locality of $G$. piperata; purple dot: only known locality for $G$. splendens; white star: type locality of $G$. coerulemaculatus; black star: type locality of Nototrema bolivianum; white dots: rest of specimens examined. See Appendix I for detailed locality data. Localities lying very close are represented by a single symbol.

Although de identity and taxonomic delimitation of Gastrotheca testudinea in Bolivia should be revised, this study is focused only on the remaining described Bolivian species: G. lauzuricae (and its senior synonym, $G$. coeruleomaculatus), G. marsupiata, G. piperata, and G. splendens (Fig. 1). While G. marsupiata is a widespread species, found mostly above the treeline (De la Riva 1992; Duellman 2015), and G. coeruleomaculatus is known only from Chaco $\left(16^{\circ} 20^{\prime} 55^{\prime \prime} \mathrm{S}, 67^{\circ} 49^{\prime} 05^{\prime}\right.$ ' W; $2042 \mathrm{~m}$ asl), in the Yungas of the department of La Paz, the other 
three taxa occur in nearby localities along the cloud forests of the Amazonian slopes of the Cordillera Oriental of the Andes in the departments of Cochabamba and Santa Cruz (Fig. 2), mostly within the boundaries of the Carrasco and Amboró national parks. Gastrotheca lauzuricae is known only from the holotype, collected at La Siberia, department of Cochabamba (De la Riva, 1992), while G. splendens is known from two specimens, the holotype (from an unknown locality), and a second specimen from Abra de la Cruz ( 17 $7^{\circ} 50^{\prime} \mathrm{S}, 64^{\circ} 20^{\prime} \mathrm{W} ; 2286 \mathrm{~m}$ asl), department of Santa Cruz (Duellman \& De la Riva 1999). In contrast, abundant specimens identified as G. piperata are known from several localities in both departments, encompassing the distribution of both G. lauzuricae and $G$. splendens (De la Riva et al. 2000) (Fig. 2).

Based on the original descriptions and subsequent relevant studies, the differences among these species would be cranial co-ossification, webbing between outer fingers, and dorsal coloration pattern (Table 1). The characters that purportedly support the distinction between G. coerulemaculatus, G. lauzuricae, G. piperata, and G. splendens are known to vary with developmental stages and derive from observations based on just one or two specimens, so that intraspecific variation is unknown except for G. piperata. As a consequence, the allocation of individuals to any of these four species remain unclear and is subjected to some degree of circularity: a certain set of character states is mostly arbitrarily assigned to a given species, so the individuals showing them pertain to such species. Given this context, the objective of this study is to review the taxonomic validity of G. lauzuricae, G. piperata, and G. splendens using cranial structures as well as other morphological characters. Since we did not have access to the type specimens of $G$. coerulemaculatus, and considering the aforementioned problems associated with Duellman's (2015) taxonomic decisions pertaining this taxon, in the Discussion we limit ourselves to add some pertinent comments and propose a provisional solution pending future studies.

\section{Materials and methods}

We examined 55 adult individuals of the genus Gastrotheca from central Bolivian cloud forests, identified as belonging to the nominal species G. lauzuricae $(\mathrm{n}=5)$, G. piperata $(\mathrm{n}=40)$, and G. splendens $(\mathrm{n}=10)$ (Appendix I). Preliminary identifications had been already done by collectors or managers of their respective collections, or were assigned by us based on published descriptions. Several specimens listed as G. marsupiata correspond to old material (from the 1920s and 1950s) preserved at the Carnegie Museum, and all of them are from cloud forest localities where G. marsupiata is mostly absent. All specimens listed in the Appendix I are identified by their catalog numbers associated with museum codes, as follows: $\mathrm{CBG}=$ Centro de Biodiversidad y Genética-Universidad Mayor de San Simón, Cochabamba, Bolivia; $\mathrm{CMNH}=$ Carnegie Museum of Natural History, Pittsburgh, USA; EBD = Estación Biológica de Doñana-CSIC, Sevilla, Spain; MNCN = Museo Nacional de Ciencias Naturales-CSIC, Madrid, Spain; and MNK = Museo de Historia Natural "Noel Kempff Mercado", Santa Cruz de la Sierra, Bolivia.

Morphology. We took nine external morphometric measurements with a digital caliper to the nearest 0.01 $\mathrm{mm}$, rounded to only one decimal and by only one person to avoid pseudo precision (Hayek et al. 2001). The morphometric variables are: snout-vent length, from the tip of the snout to the posterior margin of the vent (SVL); head length, from the jaw articulation to the tip of the snout (HL); head width, greatest width of the head at the level of the rictus (HW); internarial distance between the internal borders of the nostrils (IND); eye-nostril distance, from the posterior edge of the nostril to the anterior corner of the orbit (EN); eye diameter, greatest length of the orbit (ED); tympanum diameter, greatest horizontal distance between the edges of the tympanic annulus (TD); tibia length, from femur-tibia articulation to tibio-tarsal articulation (TL); and foot length, from the proximal edge of the inner metatarsal tubercle to the tip of the fourth toe (FL). We also examined the condition of 15 morphological external qualitative characters of 49 specimens (Appendix I) following Duellman et al. (2011) and Duellman (2015) (Table 1). We added two sets of characters to the numbered diagnosis of Duellman et al. (2011): i) snout shape in dorsal and lateral views; and ii) canthus rostralis shape in dorsal view and cross section, loreal region shape, and lips shape. We included information about coloration in preservative of head, anterior and posterior surfaces of thighs, and cloacal region. Sex and maturity of individuals were determined by the presence/absence/development of brood pouches.

Morphometric analyses. We carried out several analyses of variance (ANOVA) to assess whether the size of individuals (SVL) and six proportions of the nine morphometric variables (EN/ED, TD/ED, HL/SVL, HW/SVL, TL/SVL, and FL/SVL) between males and females of G. lauzuricae, G. piperata, and G. splendens were statistically significant. In addition, we performed two morphometric multivariate analyses based only on the nine morphometric 
variables. In order to see if these set of variables revealed a pattern of variation that is consistent with any of the taxonomic species arrangements proposed, we conducted a principal component analysis (PCA). We also performed an additional PCA in which, to prevent bias in the analysis, we previously removed the effect of co-variation of size (SVL) on the rest of variables. We made simple linear regressions between each one of the eight morphometric variables and SVL; for those variables where the SVL was significant according to the analysis of covariance, residuals obtained of those regressions were used to conduct the PCA. In both PCAs, principal components (PCs) with eigenvalues - explained variance by a PC — greater than one were retained to visually examine morphological variation among species.

Because of its property to maximize between-group variation relative to within-group variation, a linear discriminant analysis (LDA) was performed afterwards to test whether G. lauzuricae, G. piperata, and G. splendens could be discriminated efficiently from one another. Previously, we tested the correlation coefficient among all morphometric variables using the correlation matrix analysis. In order to verify univariate and multivariate normality, we used the Shapiro-Wilk test and the Royston's H test, respectively. In addition, we examined the presence of multivariate outliers using the Mahalanobis adjusted distance. We carried out a Box's M test to corroborate the homogeneity of covariance matrices. Although this analysis is quite robust for small departures from normality (Marcus 1990), we transformed the non-normal distributed variables. As LDA requires prior acknowledgement of the groups, we assigned each observation to each species following the taxonomic criteria currently in use for distinguishing these species. Because the number of samples for each species was highly unbalanced, to avoid an influence on the classification of each sample, we set the same prior probability for each species (0.33). Percent of correctly classified specimens was obtained using the leave one-out cross-validation method, which places each specimen out when its predicted group membership is going to be calculated. This procedure helped to avoid the optimistic tendency of the percent of incorrectly classified specimens that may occur as a consequence of small sample size (James et al. 2015).

Finally, to test if the cranial co-ossification development level (as observed externally) is associated to the size of individuals - inferred by SVL_- or to any of the other eight morphometric variables, we carried out several ANOVAs. For these analyses, the specimens were grouped in two categories according to their presence/absence of cranial co-ossification that is detectable externally. We used the residual values obtained before by simple linear regressions to correct the effect of co-variation of all morphometric variables with size. We tested data normality with the Shapiro-Wilk test and homogeneity of variances with the Levene's test. All statistical analyses were performed in R v. 4.0.2. To conduct the LDA we used the "lda" function of the "MASS" package (Venables \& Ripley 2002), and for the PCA the "prcomp" function of the "stats" package (R core Team 2020).

Cranial osteology. We performed micro-computed tomography (micro-CT) scanning at MNCN in order to examine and assess the skull structures of these species. This methodology is based on the emission of X-rays to create sequential cross sections images (2D) of a physical object, with a pixel size that is within the micrometer range. These images are transformed to recreate a three-dimensional volumetric map of the original object without damaging the sample (Du Plessis et al. 2017). Micro-CT scans were conducted for the skulls of six female specimens that are representative for each species: the holotype of G. lauzuricae (EBD 37379H, formerly CET [Centro de Estudios Tropicales] A501) and CBG 1019 (a specimen with external morphology highly similar to that of the holotype of G. lauzuricae); three specimens identified as G. splendens with different levels of co-ossification (CBG 1031, low level; CBG 1034, medium level; and CBG 1032, high level); and a specimen identified as G. piperata (MNKA 7157). For each scan, two specimens were introduced and positioned vertically head to head inside a closed plastic bottle. An expanded polystyrene layer was situated between them to avoid their movement during scanning, thus preventing any subsequent alteration of the image resolution. We added about $30-40 \mathrm{ml}$ of ethanol $70 \%$ at the bottom of the bottle to avoid specimen dehydration. All scans were executed using an XTH 160 Nikon Metrology, with a molybdenum target. Specimens were scanned with the following settings: $75 \mathrm{kV}$ of power, $50 \mu \mathrm{A}$ of intensity - brightness - and $30.22 \mu \mathrm{m}$ of resolution over 1000 projections during $2.00 \mathrm{~h}$ for each tomography. Raw X-ray data were elaborated using CTPro 3D software (Nikon Metrology), and morphological comparisons and visualization of the micro-CT images were performed with the free viewer app of myVGL 3.0.4 (Volume Graphics, Heidelberg, Germany).

Qualitative comparisons of the cranial osteology of individuals follow the terminology of Duellman (2015) and Duellman \& Trueb (1986). The description of cartilaginous elements such as the tympanic annulus, nasal capsules elements, and the hyolaryngeal apparatus were excluded. The general proportions of the skull were all measured at the same scale, also with myVGL 3.0.4. 


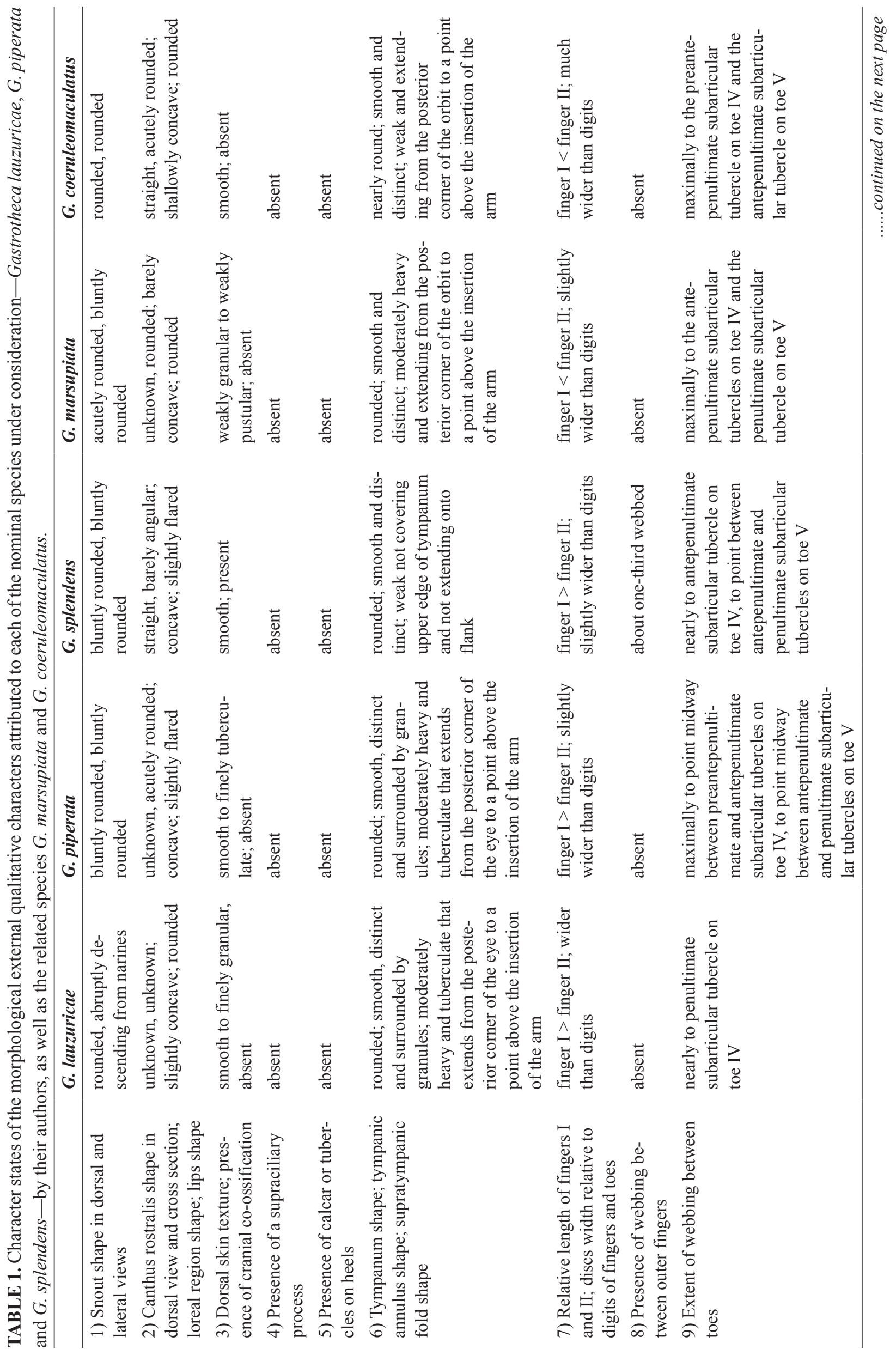




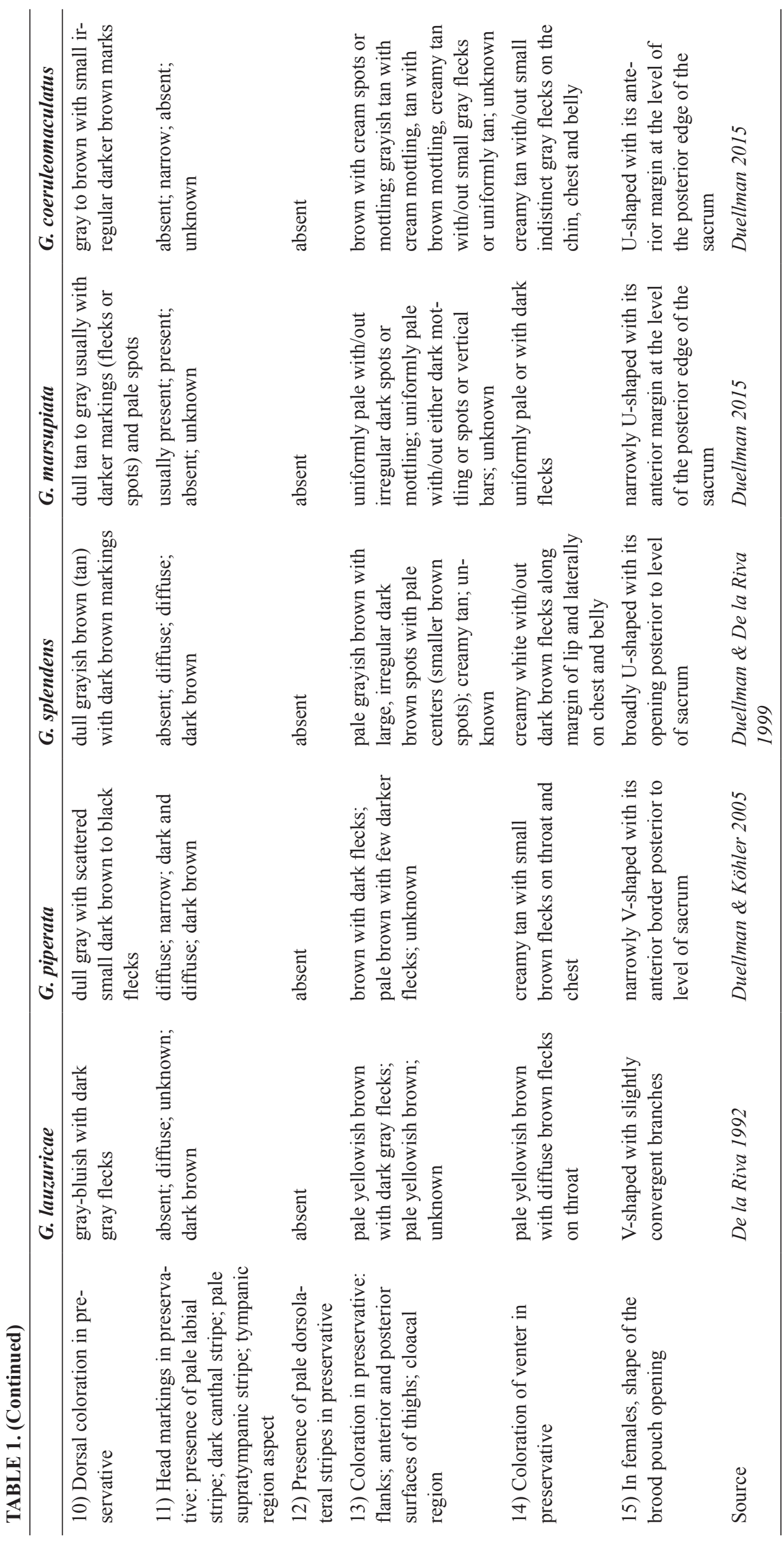




\section{Results}

External qualitative characters. A comparative detailed account of the morphological external qualitative character states and their percentages in the putative species considered is provided in Tables 1 and 2.

Morphometrics. Univariate approach. The average size of females is significantly larger than that of males (ANOVA, $P=0.001$ ), although there is some overlap between the average sizes of both sexes (Table 3). The proportion of measurements between sexes are not significantly different except for HL/SVL (ANOVA, $P=0.005$ ) and HW/SVL (ANOVA, $P=0.002$ ). $\mathrm{HL} / \mathrm{SVL}$ ratio in males (range $=0.28-0.38$; mean $\pm \mathrm{SD}=0.33 \pm 0.03$ ) is higher than in females $(0.27-0.35 ; 0.31 \pm 0.02)$; hence, males have a relatively longer head. HW/SVL ratio in males (range $=0.33-0.40$; mean $\pm \mathrm{SD}=0.38 \pm 0.02)$ is higher than in females $(0.33-0.41 ; 0.36 \pm 0.02)$; hence, males also have a relatively wider head. In all individuals, the head is wider than long, although there is some overlap in the HL/SVL and HW/SVL ratios. The tibia and foot length are the same in three individuals, while in the rest the tibia is longer than the foot. The most variable characters are EN, ED, and TD.

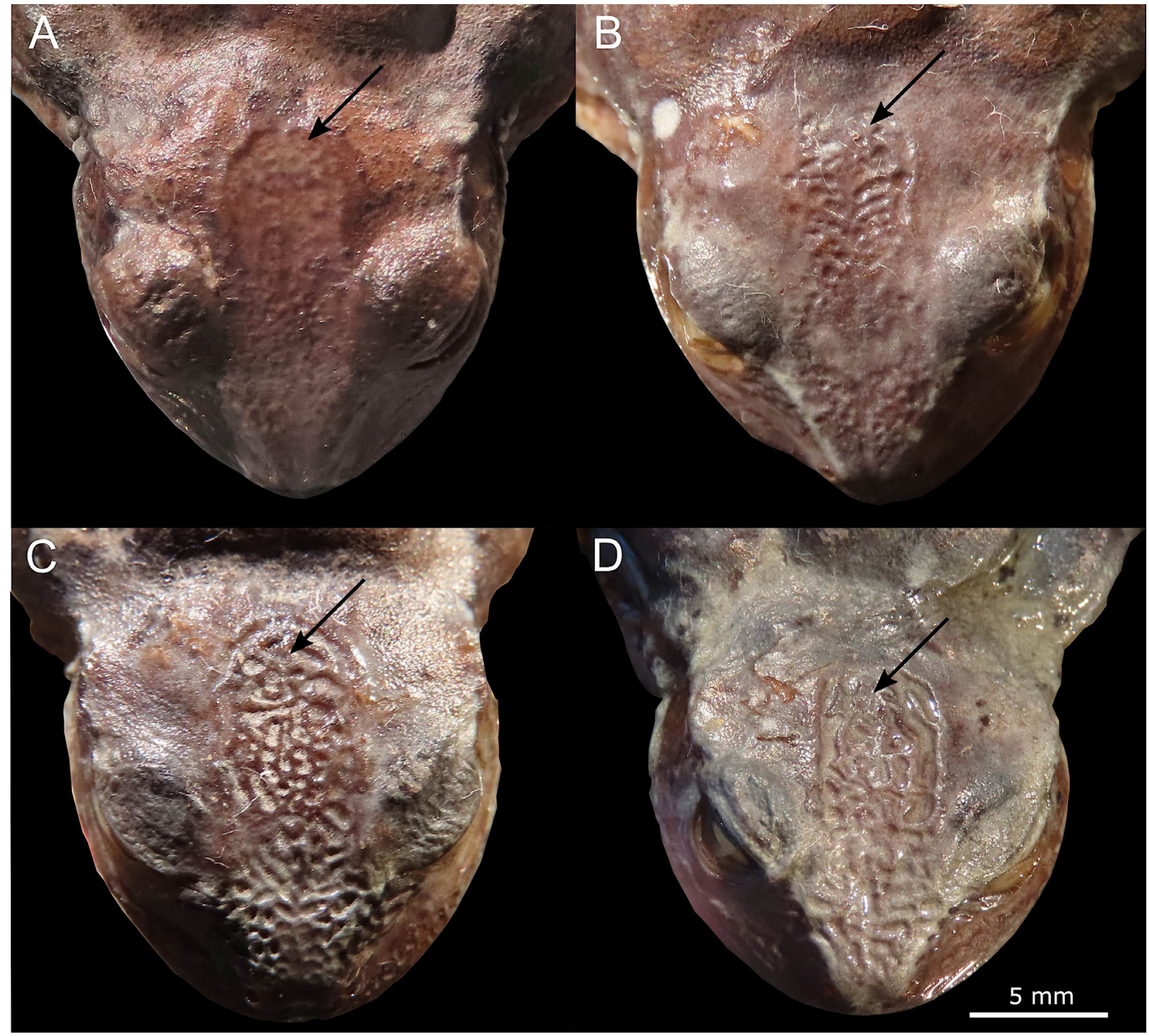

FIGURE 3. Cranial co-ossification with different degrees of development (increasing from A to D) in preserved individuals preliminary identified as Gastrotheca splendens: (A) female, CBG 1035; (B) female, CBG 1034; (C) female, CBG 1033; (D) female, CBG 1032. 


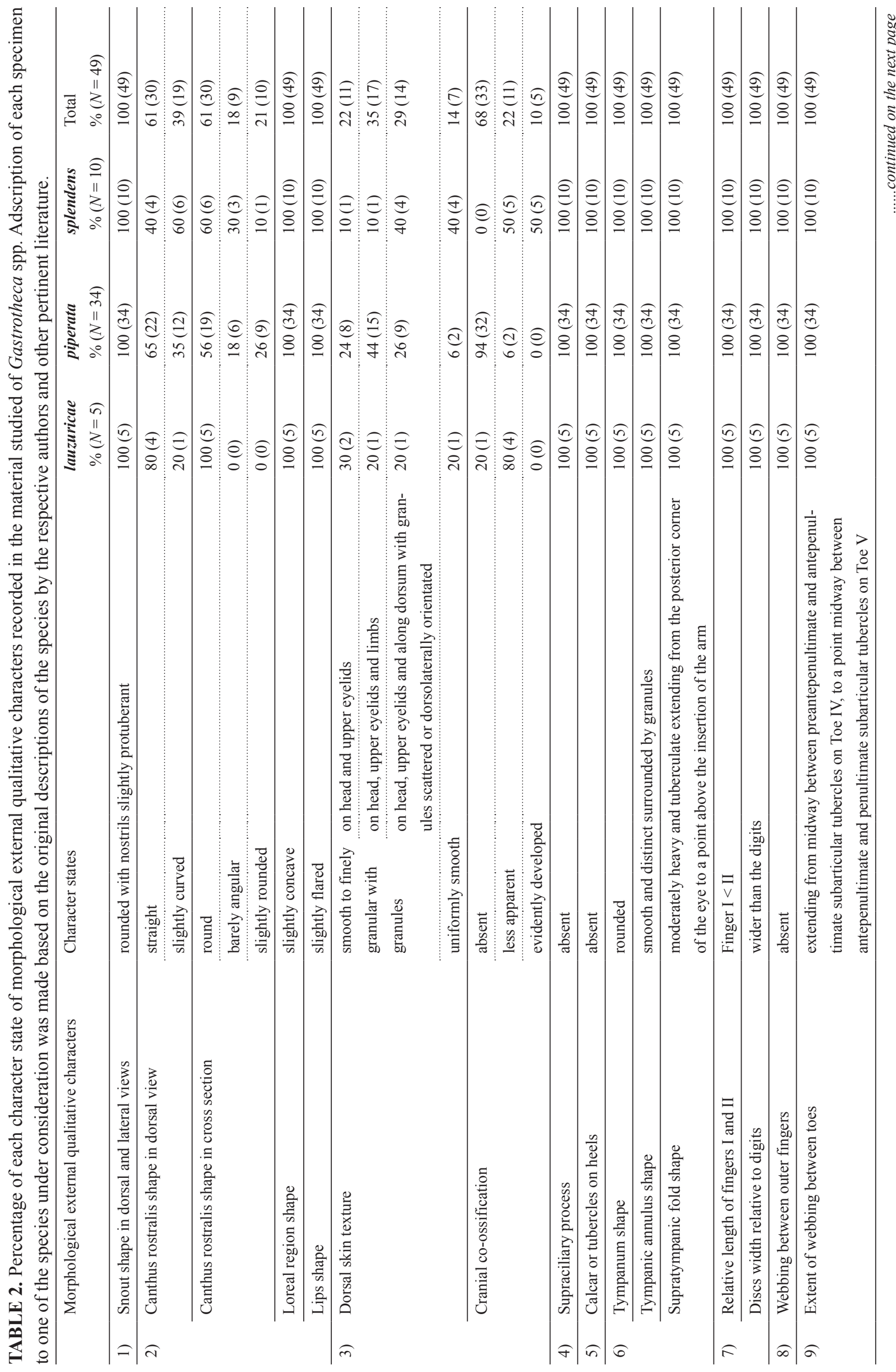




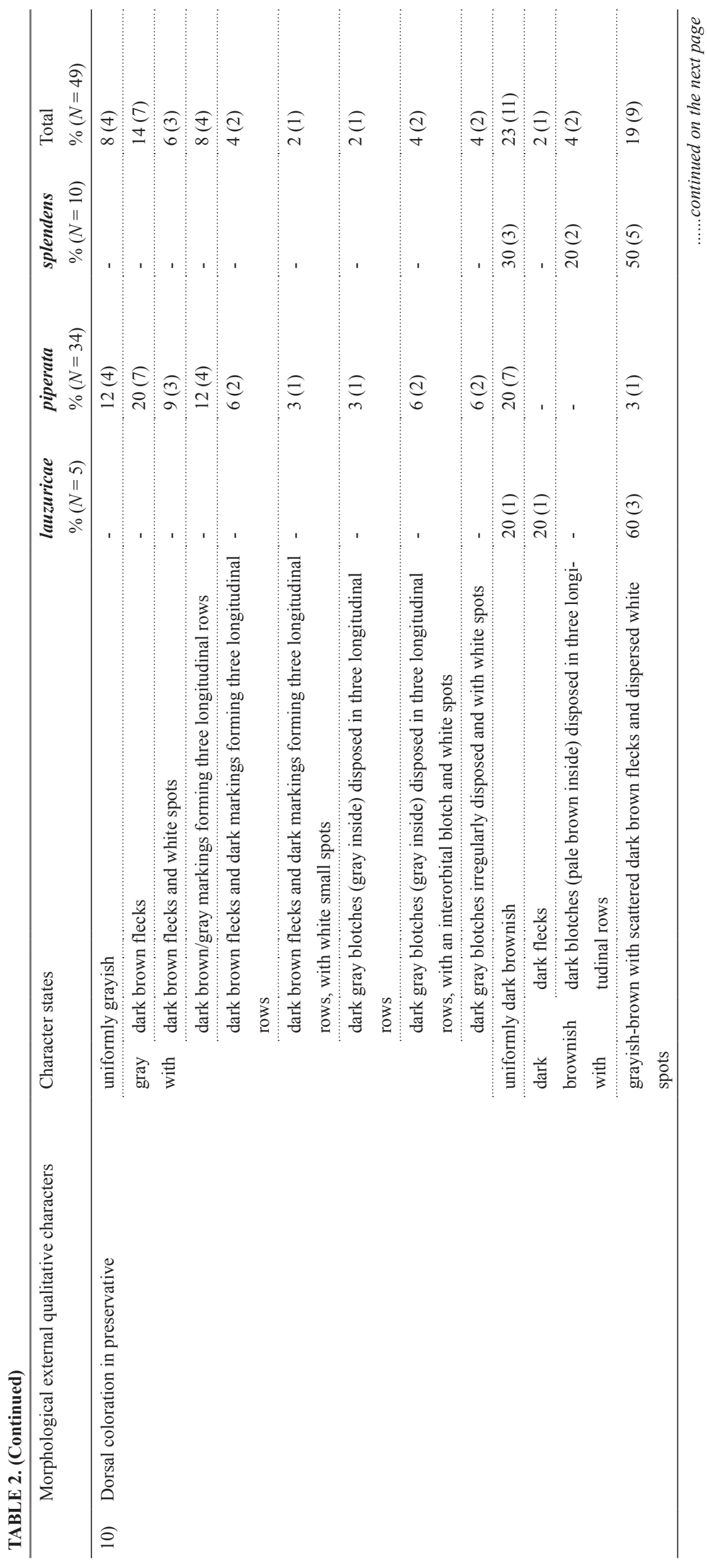




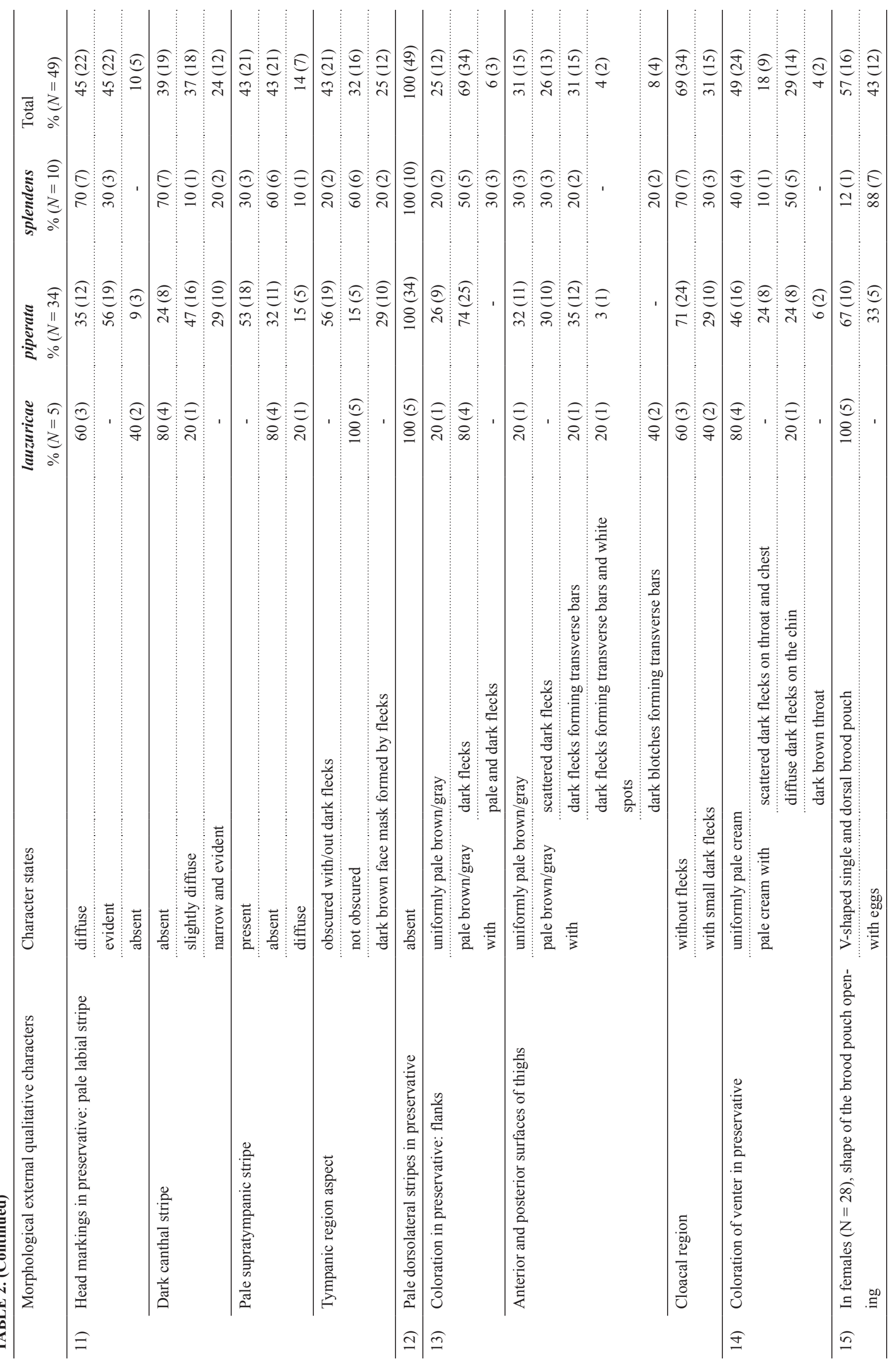




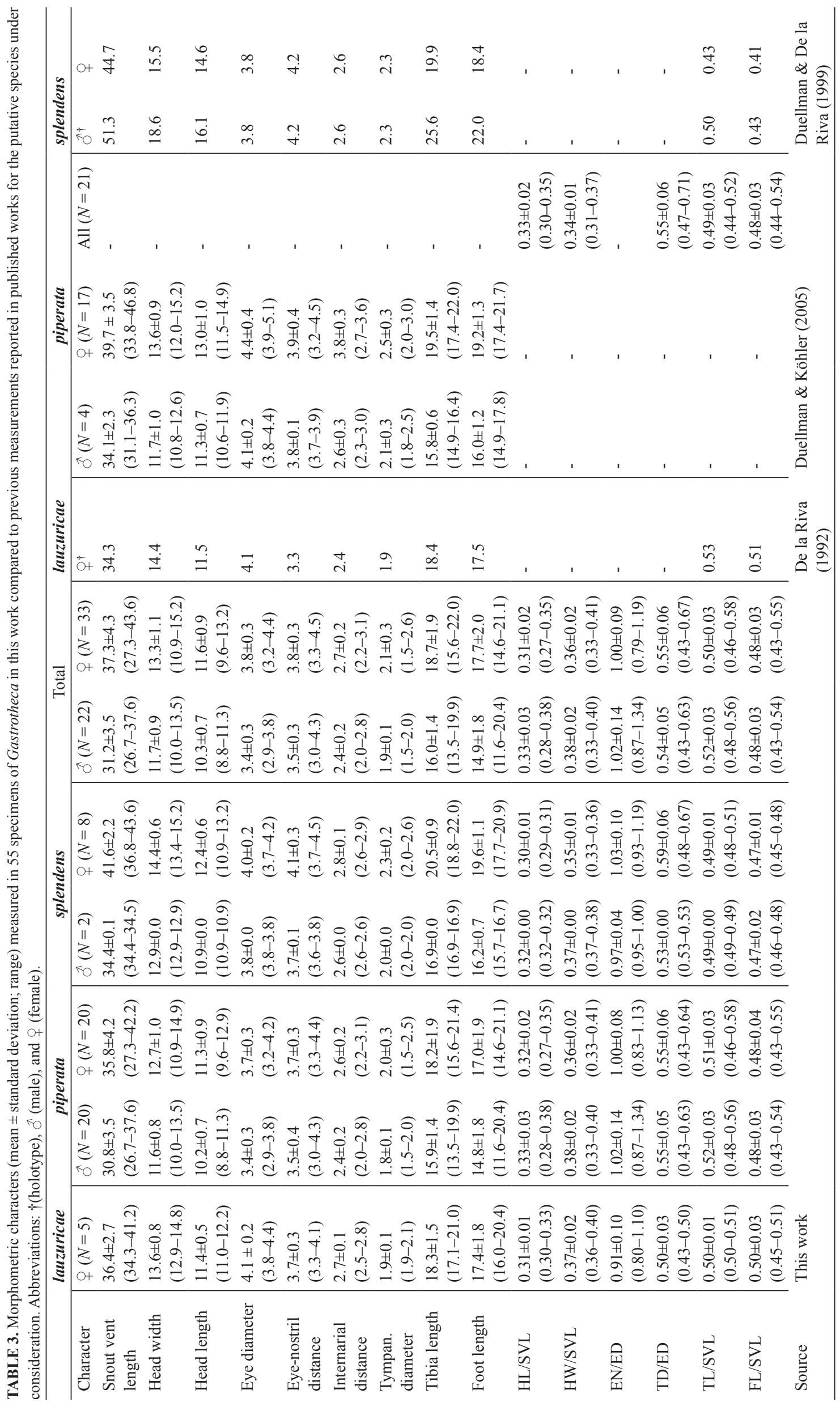


Comparing our measurements with published results, the size described for G. lauzuricae (SVL $=34.3 \mathrm{~mm}$ for the single female holotype; De la Riva 1992) and the average size of G. piperata (34.1 mm for males; 39.7 for females; Duellman \& Köhler 2005) are within the range observed by us (Table 3), but the size of specimens identified as $G$. splendens are above this range $(51.3 \mathrm{~mm}$ for the male; 44.7 for the female; Duellman \& De la Riva 1999). The TL/SVL and FL/SVL ratios of assessed individuals are similar in those of . piperata (TL/SVL $=0.49$; $\mathrm{FL} / \mathrm{SVL}=0.48)$, slightly smaller than in G. lauzuricae $(\mathrm{TL} / \mathrm{SVL}=0.53 ; \mathrm{FL} / \mathrm{SVL}=0.51)$, and slightly greater than in $G$. splendens (TL/SVL $=0.50$ for the male and 0.43 for the female; $\mathrm{FL} / \mathrm{SVL}=0.43$ for the male and 0.41 for the female). In all cases the tibia is longer than the foot.

A

B
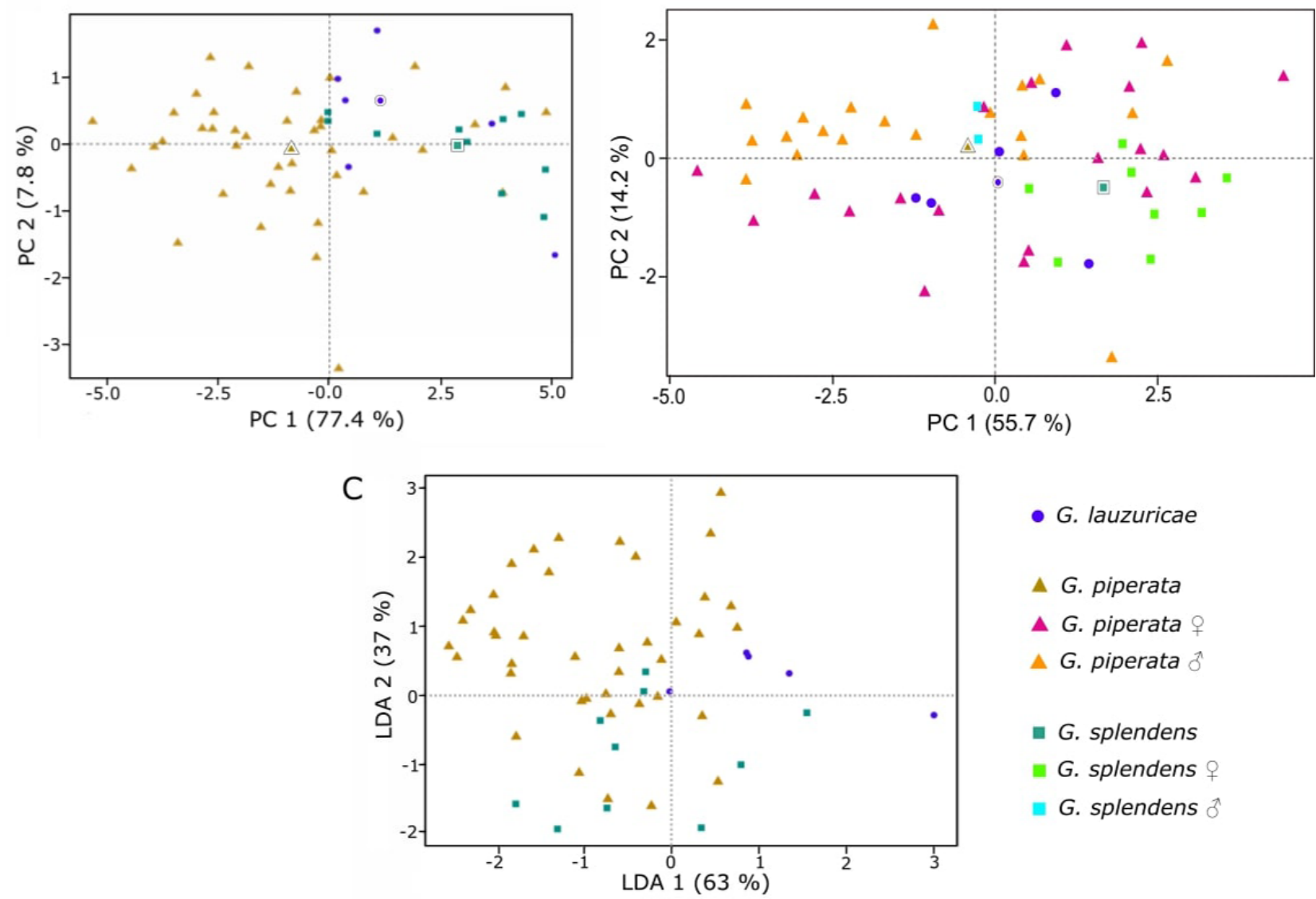

- G. lauzuricae

A G. piperata

$\Delta$ G. piperata 우

$\triangle$ G. piperata $\delta$

- G. splendens

- G. splendens 우

n. splendens $\partial$

FIGURE 4. Morphometric multivariate analyses of Gastrotheca spp. from the Yungas of central Bolivia based on nine morphometric variables $(N=55)$. (A) Principal components analysis (PCA) using unmodified variables; (B) PCA based on the residuals obtained by simple linear regressions between size and the remaining eight variables to account for the size component issue (sexes shown separately); (C) Linear discriminant analysis. Percent values indicate the proportion of variation explained by each principal component and discriminant function. Centroids of each of the species under consideration in the PCAs are indicated by the respective symbol with a white margin. A priori identifications are based on published descriptions of the species and putative differences.

Multivariate approach. In the first PCA, the first two principal components together explain $85 \%$ of the total variance (77.4 and 7.8, respectively), but only the first component presented an eigenvalue higher than one (6.9 and 0.7, respectively). The highest factor loadings in the first principal component are those of variables TL, HW, SVL, FL and HL. Variables ED, EN and IND contribute most, with high negative values, to the second principal component. The scatterplot of the 55 individuals analyzed against the first two principal components does not reveal clearly differentiated groups, with an evident overlap between them (Fig. 4A). It shows that specimens identified as G. lauzuricae and particularly G. splendens tend to have a slightly larger head width, tibia length, snout-vent length, foot length and head length; thus, a large size. Also, there is a certain degree of discontinuity in the samples along the first component, but those corresponding to the largest specimens occur in the three nominal species. Focusing on the identification, specimens labelled as G. lauzuricae tend to have large eye diameter, eye-nostril 
distance and internarial distance along to the second component, whereas those labelled as G. piperata present a high variability for all variables along the two principal components. In the second PCA, where the size component issue has been corrected, only the first two principal components presented an eigenvalue higher than one (2.24 and 1.13 , respectively) and together explain $70 \%$ of the total variance (55.7 and 14.2 , respectively). The variables that have the highest factor loadings in the first principal component are IND, SVL, ED, TD and HL, while in the second principal component are TL and FL. Compared to the first PCA, there is a higher dispersion of the points, but no pattern consistent with the species identification is apparent; labelling the sex of each specimen in the scatterplot of the first two PCs shows a significant difference in size between sexes, but gives no support to a scenario of different species either (Fig. 4B).

For the linear discriminant analysis, we exclusively considered four morphometric variables (ED, EN, IND and TD) that showed correlation values $\leq 0.8$; all of them were transformed. Although our data showed univariate (Shapiro-Wilk, $P(\mathrm{ED})=0.112 ; P(\mathrm{EN}) 0.124 ; P(\mathrm{IND})=0.300 ; P(\mathrm{TD})=0.066)$ and multivariate normality (Royston's H, $P=0.065$ ) as well as homogeneity of covariance matrices (Box's M, $P=0.05$ ), we obtained a small percentage of multivariate outliers $(6 \%)$. The first discriminant function (LD1) explained $63 \%$ of the variance whereas the second (LD2) explained 37\%. The coefficients of the variables on LD1 showed that ED (-15.2) and TD (11.3) are the most influential on this function while LD2 is also strongly influenced by TD (12.3) and to a lesser extent by EN (-5.5). Sixty-five percent of the cases were correctly classified (36 cases out of 55). However, the number of misclassified specimens is considerable high (19). Eleven of the 19 misclassifications involve specimens labelled as G. splendens that are classified as G. piperata; six specimens labelled as G. lauzuricae that are classified as G. piperata; and two specimens of G. lauzuricae that are classified as G. splendens. In the scatterplot against the two linear discriminant functions, specimens belonging to the three species are largely overlapped (Fig. 4C). According to the first discriminant function, specimens of G. lauzuricae tend to have slightly large eye diameter. The second discriminant function distinguishes G. splendens to some extent, with a small tympanum diameter, although some individuals of G. piperata are placed close to G. splendens specimens.

Cranial co-ossification and body size. The analysis of variance (ANOVA) showed that there were significant differences of size among individuals that present cranial co-ossification detectable externally and those that lack this feature (ANOVA, $P=0.0002$ ). Additionally, specimens of these two groups showed significant differences in six of the remaining morphometric variables (ANOVA, $P(\mathrm{HL})=0.035 ; P(\mathrm{EN})=0.02 ; P(\mathrm{IND})=0.01 ; P(\mathrm{TD})=$ $0.03 ; P(\mathrm{TL})=0.02$; and $P(\mathrm{FL})=0.03$.

Cranium: General proportions and shape. All specimens scanned present the osteological features shared by most members of the genus Gastrotheca (Figs. 5, 6), as distinguished by Duellman (2015). All specimens examined have a robust skull that is wider than long (11\% wider). The skulls are laterally quadrangular due to a massive temporal region, a flat skull table that extends practically to the end of the snout, hyperossified dermal roofing bones, and a massive alary process of the premaxilla (Fig. 5C, D). The greatest skull width is at the level of the articulation of the maxilla with the quadratojugal; at the anterior level of the orbit, coincident with the planum antorbitale, the width is about $79 \%$ of the greatest width. The greatest skull height is in the area of the anterior level of the otic capsule, where the height is about $48 \%$ of the skull length. Laterally, the jaw articulation lies anterior to the level of the occipital condyles in all individuals except in MNKA 7157, in which they lie posterior to them. The snout is high - about $71 \%$ of the greatest height of the skull — and elevated vertically. In dorsal/ventral view, the angle of the posterior margin of the otic capsule and crista parotica is circa $40-45^{\circ}$ from the horizontal plane. The distribution of exostosis is extensive and heterogeneous in all individuals; it is present on the sphenethmoid, nasals, frontoparietals, squamosals, and maxillae. All of them-except the sphenethmoid-are dermal bones (derived from intramembranous ossification and formed directly within the dermis from mesenchyme). The exostosis is characterized by a well-developed pit-and-ridge pattern that is less defined in the maxillae than in the other bones.

Neurocranium. All individuals present a substantial and well ossified endocranium (Figs. 5, 6). The septomaxillae are large - except in CBG 1019 that are smaller-triradiate paired bones encapsulated within the cartilages of the nasal capsule (thus, they lack articulation with other bones) (Fig. 5D). They have an extended anterior process and two posterior processes; the posterolateral process is more elaborated than the posteromedial. In EBD 37379H, CBG 1019 and CBG 1034 the posterolateral process of this bone has three protuberances, while in CBG 1032, MNKA 7157 and CBG 1031 is elongated. The braincase is composed by a robust sphenethmoid that is co-ossified with the overlying skin (Figs. 5,6), and exostosed dorsally with a well-developed irregular pit-and-ridge pattern; it has larger and irregularly shaped pits in CBG 1031, CBG 1032, and MNKA 7157. Only 
in EBD $37379 \mathrm{H}$ the sphenethmoid is synostotically fused with the adjacent nasals and frontoparietals, caused by development of exostosis. The sphenethmoid is complete dorso- and ventromedially; its ossification extends anterior to the planum antorbitale so that it underlies the posterior part of the vomer, and posterior to the planum antorbitale so the orbitonasal foramen has a complete bony margin. The posterior margin of the bony sphenethmoid lies ventrally, nearly posterior to the mid length of the orbit. The prootic and the exoccipital are extensively ossified and well-developed (Figs. 5A, 6). Ventrally, they are synostosed with the underlying parasphenoid exclusively in EBD $37379 \mathrm{H}$ and CBG 1019. The exoccipitals are complete and fused medially in their dorsal and ventral aspects; the epiotic eminences are prominent. The margin of the foramen magnum is complete in bone. The otic capsules are completely ossified; the crista parotica is long and slender in posterior view, broad in dorsal/ventral view and complete to the head of the squamosal. The middle ear is wide, marked by the crista parotica of the prootic. There is a plectral apparatus composed of a pars interna plectri, and a pars media plectri (stylus or stapes). Generally, the pars media plectri is slender - extremely thin in CBG 1019-and extends dorsolaterally from the fenestra ovalis towards the tympanum (Fig. 5). In CBG 1031, CBG 1034 and MNKA 7157, the distal end of the stylus is overlapped by the articulation of the crista parotica with the squamosals. The pars interna plectri is located in the anterodorsal part of the fenestra ovalis; posteriorly, its dorsal part is either 2-3 times broader than the ventral portion in all the individuals. Three of the specimens, EBD 37379H, CBG 1019, and MNKA 7157, present an operculum situated between the pars interna plectri and the anterodorsal part of the fenestra ovalis. In CBG 1019 the plectral apparatus is hypperosified.

Dermal investing bones. The nasals are expanded and present exostosis in form of a well-developed irregular pit-and-ridge pattern (Figs. 5A, C, D, 6), with larger and irregularly shaped pits in MNKA 7157. These bones extend anteriorly over the rostrum and ventrolaterally to cover the nasal capsule nearly completely in all specimens. The maxillary process articulates with the preorbital process of the pars facialis of the maxilla, forming a bony anterior margin of the orbit. In EBD 37379H, CBG 1019 and MNKA 7157, the nasals are dorsally synostotically united to one another and to the sphenethmoid, owing to the development of exostosis. In the rest of individuals, the nasals have nearly a complete medial articulation and overlap the anterolateral margins of the sphenethmoid. The frontoparietals are exostosed in form of a well-developed irregular pit-and-ridge pattern (with larger and irregularly shaped pits in CBG 1031, CBG 1032, and MNKA 7157). They have a complete medial articulation with one another, extending from the sphenethmoid posteriorly to the occiput in the region of the foramen magnum (Figs. 5A, 6). However, in EBD 37379H, CBG 1019 and MNKA 7157 the frontoparietals are synostotically united to one another dorsally. Additionally, these bones present "casquing", characterized by a narrow and scarcely evident supraorbital flange - progressive marginal expansion - that lies at the mid length of the orbit; it is more pronounced in EBD 37379H, CBG 1031, CBG 1034, and MNKA 7157. The posterolateral margins of the frontoparietals are not fused with the underlying dorsal surface of the epiotic eminences, thus the carotid canal is open in all the individuals. The frontoparietals do not present an otic flange, neither a complete temporal arcade (they do not articulate with the head of the squamosal). All individuals present an elaborated parasphenoid with a broad corpus (Figs. 5B, 6). Its cultriform process is long, terminates slightly posterior to the levels of the neopalatines -at the level of the orbitonasal foramina-, and it narrows gradually in the anterior part of the orbit. The anterior terminus of this process is blunt in all specimens, except in CBG 1031, that presents an acuminate terminus. The two alary processes are relatively long, posterolaterally oriented $\left(100-110^{\circ}\right)$, and narrowly separated from the medial ramus of the pterygoid. The posteromedial process of the parasphenoid is moderately-sized and rounded. The neopalatines are robust and well-developed, underlay the planum anterorbitale, and form a bony posterior margin to the choana (Figs. 5B, 6), each bone articulating laterally with the lingual face of the pars facialis of the maxilla. Anteriorly, these bones are scarcely convex, separated medially from one another, and each of them ends with an acute terminus that lies on the lateral sphenethmoid anterior to the orbitonasal foramen. Its ventral surface bears a flange, whose edge is irregularly denticulate. The vomers are elaborated and dentate, and form part of the palate and floor the premaxillae and maxillae anteriorly and the sphenethmoid posteriorly (Figs. 5B, 6). The vomerine corpus is broad, except in CBG 1019 and CBG 1034, where it is narrower; it is smooth in all individuals except in CBG 1032, which presents an irregularly dentate corpus. The anterior process of the vomer floors the anterolateral portion of the olfactory organ; it extends to the maxillary arcade, connecting with the pars facialis of the maxilla in EBD 37379H and CBG 1031, while in the rest of individuals the anterior process does not contact this bone. This process is elongated except in CBG 1034 and MNKA 7157, in which is wider and robust. The pre- and postchoanal processes of the vomer support the anterior and the medial margins of the choana. The prechoanal process is long and supports 
the entire anterior margin of the choana, but it is clearly separated from the lingual surface of the pars facialis of the maxilla. In CBG 1019 and CBG 1032 this process is shorter and supports nearly completely the anterior margin of the choana. The postchoanal process lies adjacent to the bony sphenethmoid along the medial margin of the choana. This process is short and forms only about half of the medial margin of the choana, with which it is slightly fused. The dentigerous process is moderate in size in EBD 37379H, CBG 1019 and CBG 1034, whereas in CBG 1031, CBG 1032 and MNKA 7157 is markedly large. It bears 3-4 pedicellate and rounded teeth in EBD 37379H and CBG 1034; 5-6 in CBG 1019, CBG 1031 and CBG 1032; and 7-8 in MNKA 7157. The teeth are sharper in CBG 1019. The dentigerous processes are transversely oriented, and lie at the level of the posterior margin of the choana in EBD 37379H, CBG 1031, CBG 1034 and MNKA 7157. However, in CBG 1019 and CBG 1032, the medial ends of the processes lie posterior to the lateral ends, and are situated at about the midlevel of the choana. These processes are narrowly separated from one another except in CBG 1034, in which the separation is wider.

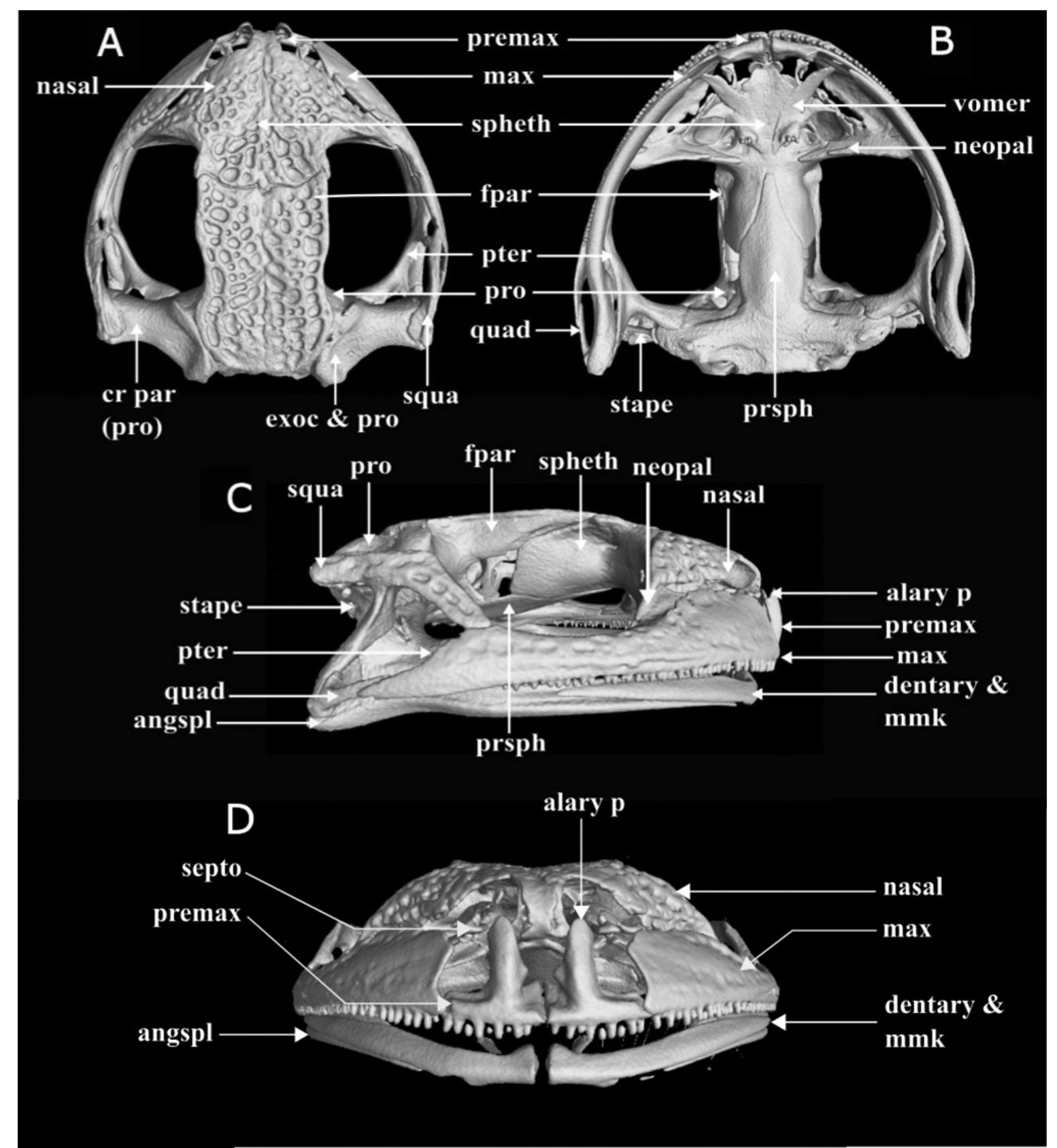

FIGURE 5. CT-scan images of the skull of a specimen identified as Gastrotheca splendens (CBG 1034) in dorsal (A), ventral (B), lateral (C), and frontal view (D) with the principal bones indicated. Abbreviations: alary $\mathrm{p}=$ alary process; angspl = angulosplenial; $\mathrm{cr}$ par $=$ crista parotica; exoc $=$ exoccipital; $\mathrm{fpar}=$ frontoparietal; $\max =$ maxilla; $\mathrm{mmk}=$ mentomeckelian bone; neopal = neopalatine; premax $=$ premaxilla; pro = prootic; prsph $=$ parasphenoid; pter $=$ pterygoid; quad $=$ quadratojugal; septo $=$ septomaxilla; spheth $=$ sphenethmoid; squa = squamosal. Images not at the same scale. 


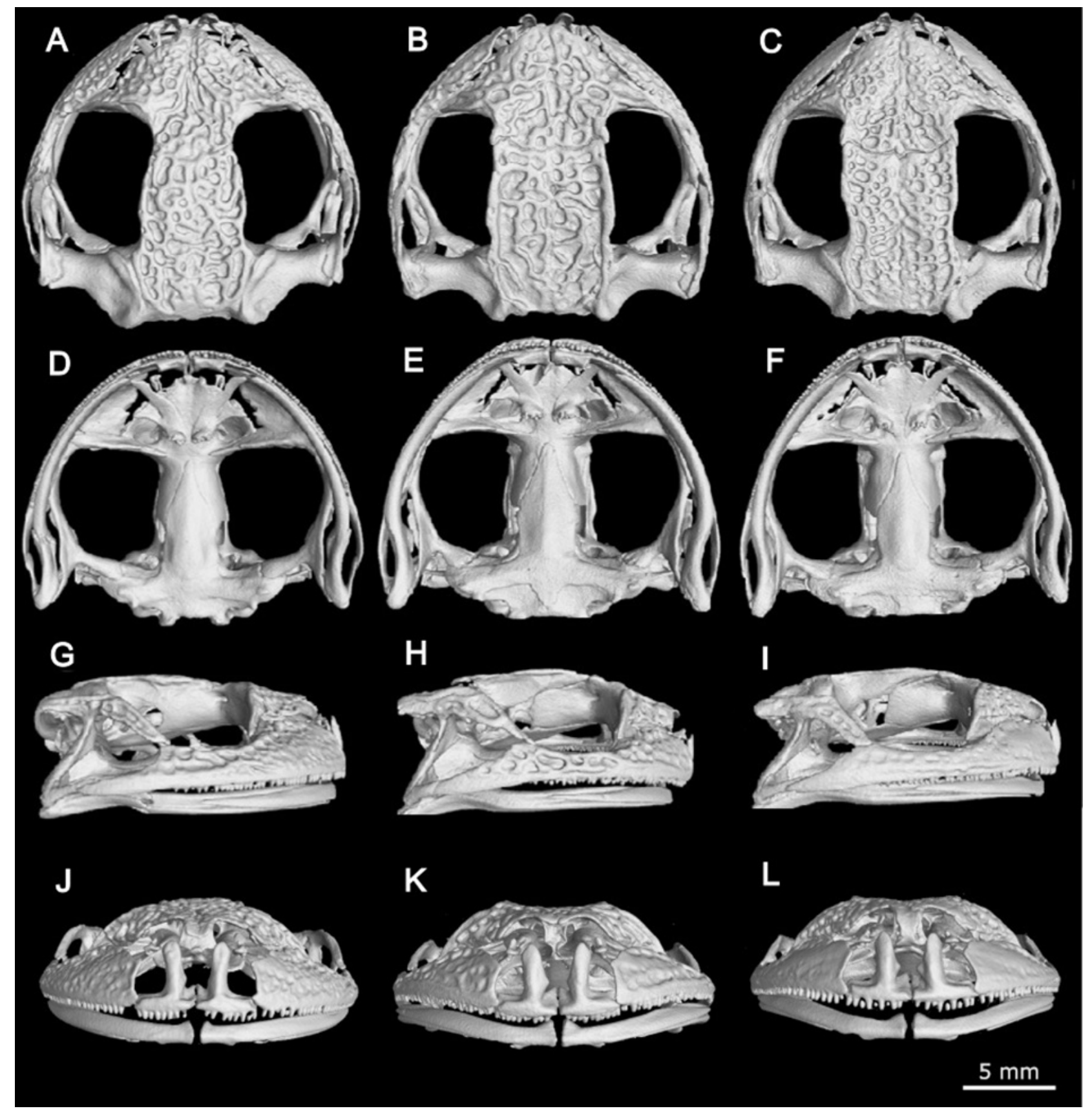

FIGURE 6. CT-scan images of the skulls of three putative species of Gastrotheca from the Yungas of central Bolivia: (A, D, G, J) Gastrotheca lauzuricae, EBD 37379H, female holotype, 34.3 mm SVL; (B, E, H, K) G. piperata, MNKA 7157, female, 39.5 mm SVL; (C, F, I, L) G. splendens, CBG 1034, female, $41.8 \mathrm{~mm} \mathrm{SVL}$. From top to bottom: dorsal, ventral, lateral and frontal views; note the variation in the extent of hyperossification (in form of exostosis).

Maxillary arcade: This structure is complete and the upper jaw is composed of robust premaxillae, maxillae, and quadratojugals. The expanded quadratojugals are broadly overlapped laterally by the maxilla and subtends about the middle of the subtemporal fenestra (Figs. 5B, C). The maxilla has a well-developed pars facialis that is exostosed with an irregular pit-and-ridge pattern gradually more accentuated on its lateral and upper regions (Figs. 5A, C, D); it is less defined in CBG 1031, CBG 1034 and CBG 1032. The maxilla bears a postorbital process that articulates with the zygomatic ramus of the squamosal at the posterior margin of the orbit. The preorbital process of the pars facialis is well-defined and firmly articulated with the maxillary process of the nasal. The pars palatina is narrow and elaborated posteriorly into a distinct medial process that articulates with the anterior ramus of the pterygoid. The premaxilla is broad and bear a robust and elongated alary process that is nearly vertical, except in CBG 1019 and CBG 1032, whose processes are slightly anteriorly deflected at an $5^{\circ}-10^{\circ}$ angle; the terminus of the 
alary process is rounded (Fig. 5C, D). The pars palatina is relatively narrow and is medially elaborated into a medial palatine process longer than the lateral palatine process. The pars dentalis of the maxilla slightly overlaps the lateral end of the pars dentalis of the premaxilla; both structures show bicuspid teeth (moderately sharp in CBG 1019). The pars dentalis of the maxillae are present along most of their complete length, and bear about 40 teeth each -30 in CBG 1019-; each of the pars dentalis of the premaxillae bear 6-9 teeth.

Suspensory apparatus: One endochondral bone-formed indirectly by the replacing of embryonic cartilage with bone - , the palatoquadrate, and three paired dermal bones — the squamosals, pterygoids and maxillae-, sustain and reinforce the maxillary arcade. The palatoquadrate is attached to the margin of the crista parotica and the head of the squamosal overlies it. The massive squamosal present exostosis in form of a pit-and-ridge pattern with irregularly shaped and broad pits, that are more defined in its head and its zygomatic ramus (Fig. 5C). The otic plate is wide and covers approximately 60\% of the width of the crista in EBD 37379H and CBG 1034; 80\% in CBG 1019 and CBG 1032; and completely in CBG 1031 and MNKA 7157. The zygomatic ramus extends anteroventrally from the head of the squamosal and articulates with the pars facialis of the maxilla at the posterior margin of the orbit. This ramus is laterally broad and hyperossified, and articulates with the postorbital process of the maxilla through a large diagonal connection; this articulation is narrower in CBG 1019 and MNKA 7157. The angle described by the ventral ramus and the horizontal plane of the maxilla is between $50-60^{\circ}$. The triradiate pterygoid connects the anteroventral margin of the otic capsule with the medial surface of the palatoquadrate, and with the lingual margin of the maxilla in the postorbital region (Fig. 5B). The medial and posterior rami are about equal in length in ventral aspect; the anterior ramus is slightly curved, extends anteroventrally, and exhibits a dorsal process. This process is uniform in width, ends bluntly and articulates with the medial surface of the postorbital process of the maxilla in CBG 1019 and CBG 1032. In the rest of individuals, the dorsal process articulates with the zygomatic ramus of the squamosal as well (in CBG 1031 the dorsal projection is broader).

Mandible: The lower jaw is composed by three paired bones, the angulosplenials, dentaries, and mentomeckelian bones (Figs. 5C, D, 6). The angulosplenials are long (extending to the $80 \%$ of the total length of the mandible), their lateral side is posteriorly concave and anteriorly convex, and they articulate with the quadratojugal posteriorly. The dentaries are fused with the robust mentomeckelians; posteriorly, the dentaries narrow gradually -abruptly in the case of CBG 1019- to end flat and pointed, extending closely to the middle of the angulosplenials. The mentomeckelians are short and wider anteriorly, and articulate with one another by a cartilaginous joint.

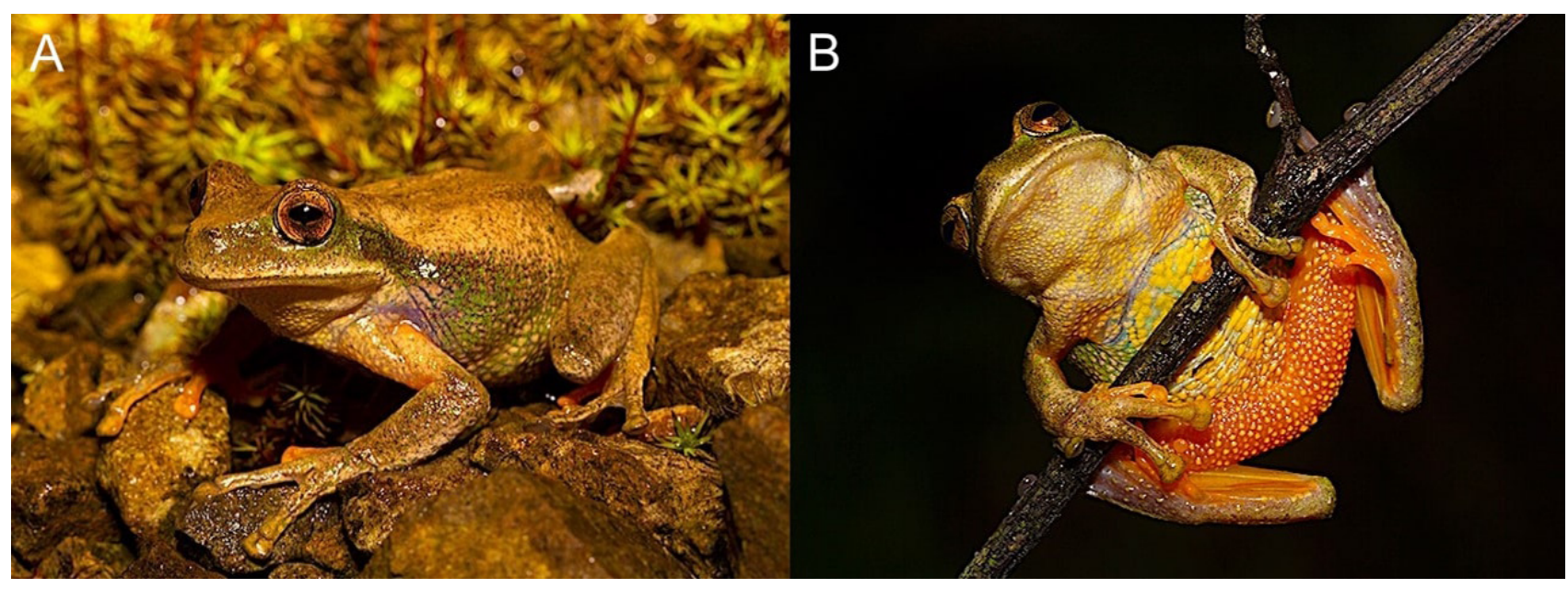

FIGURE 7. Female alive specimen belonging to the Gastrotheca populations from the cloud forests (Yungas) of department La Paz (Bolivia) for which the name G. coerulemaculatus (Werner, 1899) is available. A) Dorsolateral view; B) ventral view; note the blue, green, and yellow ventral pattern, and the orange lower surface of thighs (Photos: Mauricio Pacheco).

\section{Discussion}

In previous taxonomic works, Gastrotheca lauzuricae, G. piperata, and G. splendens have been mostly differentiated in terms of size, presence of cranial co-ossification, webbing between outer fingers, and dorsal pattern coloration (De la Riva, 1992; Duellman \& De la Riva 1999; Duellman \& Köhler 2005; Duellman 2015). Records of these species indicate that they occur within the same altitudinal range $(\sim 1850-2800 \mathrm{~m})$ in the Bolivian cloud forests of 
the departments of Cochabamba and Santa Cruz (De la Riva et al. 2000; Köhler 2000). It must be noted that, while the description of G. piperata is based on more than twenty specimens (Duellman \& Köhler 2005), the description of G. splendens is based exclusively on two - one of each sex-(Duellman \& De la Riva 1999), and that of $G$. lauzuricae only on one female (De la Riva 1992). Our field experience, observations and data of Gastrotheca frogs from the Andean cloud forests of central Bolivia, plus the analyses presented herein, suggest that the recognition of three species in the area may be unjustified. The necessity of a reassessment of the taxonomic status of central Bolivian populations of Gastrotheca was clearly stated by Castroviejo-Fisher et al. (2015) and Echevarría et al. (2021), who in their analyses provisionally labelled some samples from this region as Gastrotheca sp.1, G. sp. 2 and $G$. sp. 3. Despite their internal relationships not being clearly resolved, all were shown to be closely related and part of a subclade containing G. marsupiata plus the three nominal species known from northern Argentina $(G$. christiani Laurent, 1967, G. chrysosticta Laurent, 1976 and G. gracilis Laurent, 1969), which appear to be genetically very close to Bolivian G. marsupiata; however, differences in morphometry, color patterns, development, and advertisement calls have been amply documented (e.g., Cei, 1980; De la Riva et al. 1995; Akmentins et al. 2014; Akmentins \& Boullhesen 2020).

External characteristics. Our results do not show strong discrepancies in relation to the average size previously reported for each species. The known average size (SVL) of G. piperata (and the SVL of the holotype of $G$. lauzuricae) is within the average size range that we obtained for the whole data set studied (Table 3), yet the size of specimens identified as G. splendens are slightly above this range. Accordingly, the mean tibia and foot lengths in relation to SVL of assessed individuals are similar in G. piperata and G. lauzuricae, and slightly greater than in G. splendens. In all cases the tibia is longer than the foot.

The multivariate approach does not provide a picture consistent with the recognition of the three assessed names either. Neither principal component analyses nor linear discriminant analyses produced discrete clusters corresponding to a priori identifications of G. lauzuricae, G. piperata and G. splendens, although these results could be biased to some extent by the unbalanced number of individuals of each species. The first axis of the first PCA (based on unmodified variables) explained most of the overall variance (77.4\%), and is a typical size component since it is associated with all the morphometric variables that are strongly correlated with SVL. If we examine each of the proposed species independently, the results suggest a slight tendency of specimens identified as $G$. splendens to be larger, and those of G. lauzuricae to have a longer eye diameter. However, those values fall within the range of variation of $G$. piperata. The results of the second PCA, in which we corrected the size component issue, showed more dispersion among points than in the first PCA, but did not support the differentiation between the species either. If in this analysis we consider the sex of each specimen, our results indicate that females are larger both in general and when considering two of the species under consideration (of G. lauzuricae we only have females). However, this pattern does not provide any clear support for the recognition of these species. The LDA, in which-unlike PCA-identifications based on the reported taxonomic criteria of the putative species are considered, classified correctly $65 \%$ of the individuals. This is a relatively low percentage given that this analysis is meant to maximize discrimination among predefined groups. Besides, the better discrimination of G. piperata obtained in the percent of correctly classified specimens is likely influenced by the higher number of specimens labelled as G. piperata. Even assigning the same prior probability to each of the three species, since G. piperata pre-identified specimens span a large part of the multivariate space, this species may have "confounded" specimens pre-identified as G. lauzuricae and G. splendens that lie in doubtful or intermediate areas of that multivariate space.

Although we could appreciate more morphological similarities than disparities between individuals, some highly variable external qualitative characters (dorsal texture, dorsal coloration pattern in preservative, and presence of cranial co-ossification) are noteworthy. Most individuals present a smooth to finely granulate skin on dorsum, as was described for G. lauzuricae, with scattered granules on head and upper eyelids as described in G. piperata. Yet a few individuals exhibited a smooth dorsum consistent with the description of $G$. splendens. The dorsal coloration in preserved specimens was grayish in most specimens, as in G. piperata and G. lauzuricae descriptions, brown in others, and grayish-brown in the rest, as in G. splendens description. Some individuals additionally present dark markings, flecks and/or spots on dorsum - scattered or dorsolaterally oriented-, and defined or diffuse transverse dark markings on forearms and thighs. Therefore, although dorsal coloration pattern differed highly among studied specimens, it is in concordance with the intraspecific variability previously reported in G. piperata (Duellman \& Köhler 2005), and with the coloration pattern described for G. lauzuricae and G. splendens (De la Riva 1992; Duellman \& De la Riva 1999). 
Osteology. It has been recently stated that most species of Gastrotheca present some degree of co-ossification (Duellman 2015). In this study, we have observed well-developed cranial co-ossification in some specimens, as originally reported for G. splendens (Fig. 3; Duellman 1970; Duellman \& De la Riva 1999). However, we found no apparent association of the cranial co-ossification with the extent of the webbing between outer fingers (webbing is absent in the specimens examined), which may be a character showing some degree of intraspecific variation. The variance observed in these external qualitative characters could be related to the ample intraspecific variability that exists for several characters in many species of anurans (Duellman \& Trueb 1986). Thus, if we considered that the studied specimens may belong to the same biological entity, the variation observed could be easily explained.

Cranial co-ossification - the most extreme expression of hyperossification-does not seem to support a distinction between the three purported species studied and it could be related to the development state of individuals. Larger specimens have a higher probability of co-ossification, which supports that the best explanation for this skull character is age (development) or bone mineralization associated with diet which could also influence size.

Although hyperossification in general is not correlated with size in anurans (for example, small species like the brachycephalid frog Brachycephalus ephippium [SVL less than $16 \mathrm{~mm}$; Clemente-Carvalho et al. 2009] have a heavily ossified skull), cranial co-ossification in particular has been strongly related with development in many groups of anurans (e.g., Wild 1997). A likely reason for this is that, as individuals develop, the bone forms in the dermis of the skin, and then it fuses with the underlying cranial bone so that the skin in the adult is united completely to the underlying bone (Duellman \& Trueb 1986). Our results support this scenario since we obtained significant differences of size (SVL) between individuals that present externally detectable cranial co-ossification (32\%) and those in which it is not detectable externally, and most of the remaining morphometric characters also revealed significant differences between these two groups.

All individuals scanned present exostosis - a rudimentary form of hyperossification —on the dermal bones of the skull (sphenethmoid, frontoparietals, nasals, maxillae, and anterior rami of squamosals). Consequently, all of them present cranial co-ossification, as this feature has been associated with the presence of exostosis on the dermal sphenethmoid (Duellman 2015). All individuals have slightly elevated lateral edges of the frontoparietals as described for G. splendens (Duellman \& De la Riva 1999). We observed that the most variable feature among individuals is related to the dermal bones that are synostosed (i.e., fused) one to another. For instance, the nasals, frontoparietals, and sphenethmoid are entirely synostosed in the G. lauzuricae holotype only, whereas in a specimen identified as G. splendens none of them are fused. This variation is seemingly caused by the different extent of hyperossification presented in each individual. Additionally, we noticed the augmentation and deformation of several bones such as vomers, squamosals, and plectral apparatus of the middle ear, presumably due to hyperossification (Duellman \& Trueb 1986). Thus, the variation observed in the osteological characters do not support conclusively the distinction of the three nominal species, which would support the suspicions of Trueb (1973), and Duellman \& Trueb (1986) that these structures do not have a high taxonomic value at species level.

In vertebrates, the skull may be sexually dimorphic in terms of size and shape induced by sexual selection (Herrel et al. 2001). We could not assess whether the skull structures of individuals scanned exhibit some evidence of sexual dimorphism because all of them were females (but, on the other hand, this fact enabled the comparison among them). Further research including the skull of both sexes would be convenient.

Taxonomic conclusions and remarks. We consider that the external and internal morphological evidence analyzed herein indicates that Gastrotheca populations from the Andean cloud forests of central Bolivia (departments of Cochabamba and Santa Cruz) currently recognized under the nominal species G. lauzuricae, G. piperata, and G. splendens, belong to a unique biological entity, for which the name Gastrotheca splendens (Schmidt, 1857) has priority; thus, G. lauzuricae De la Riva, 1992 and G. piperata Duellman \& Köhler, 2005 become junior synonyms. Further robust molecular analyses and a more comprehensive taxonomical revision —including more specimenswould be advisable to support our proposition of the reunification of these three names into a single species.

It must be said that specimens of G. piperata from the westernmost limit of the distribution of the species (province of Chapare, Cochabamba) were not included in the type series by Duellman \& Köhler (1995). Instead, in their Appendix 1 they cited only one specimen (AMNH 34033) from that area (Incachaca, $2500 \mathrm{~m}$ ), which was not collected by them. However, they stated that advertisement calls described by De la Riva et al. (1995) for frogs from a nearby locality (Tablasmontes) were identical to those from a locality in the core region of the distribution of G. piperata (Karahuasi, province Carrasco, Cochabamba). Twenty-four specimens from the Chapare area were included in our analyses and their morphometric characteristics match those of the other populations considered, thus 
supporting our view of a single species from the morphological standpoint. Nevertheless, preliminary molecular data (De la Riva et al., unpublished), although supporting our general conclusions based on morphology, indicate that Chapare populations might belong to a different species, for which the name Gastrotheca bolivianum (Steindachner, 1892) would be available, a topic that will be the subject of future research.

Once the situation of the three cloud forest species considered above has been clarified, one must wonder what happens with the name G. coeruleomaculatus. Duellman (2015) did not make direct comparisons of the types of G. coeruleomaculatus and G. lauzuricae, and based his conclusion on the published descriptions only, both of which mention the presence of blue spots. However, the type locality of G. coeruleomaculatus is Chaco (16 $20^{\prime} 55^{\prime \prime}$ $\mathrm{S} / 67^{\circ} 49^{\prime} 05^{\prime}$ 'W), in the Yungas of the Department of La Paz, $\sim 370 \mathrm{~km}$ airline apart from that of G. lauzuricae. This represents a long distance in terms of distribution patterns of cloud forests amphibians from Bolivia, where there are several instances of species turnover as we move from the forests of Santa Cruz and Cochabamba to those of La Paz (likely due, at least in part, to the role of biogeographic barriers like the broad and arid Valle de La Paz [see De la Riva 2000]). Other than the widespread species G. marsupiata, found mostly above the treeline (De la Riva 1992), and the rare G. testudinea, for which only a few Bolivian records are known, no records of Gastrotheca have been known for decades in the Yungas de La Paz region. Thus, the description of Hylodes coeruleomaculatus by Werner in 1899 has remained puzzling. However, the same author described in the same publication (Werner 1899) other rare and elusive anuran species which have been only recently well documented and studied, such as Telmatobius verrucosus and Yunganastes bisignatus (De la Riva 2005; Ocampo et al. 2020). The locality of Chaco lies at a relatively low elevation (2042 $\mathrm{m}$ asl), and it is possible that some of the specimens described by Werner actually came from surrounding localities at higher elevations; for example, Telmatobius verrucosus is known to occur only in the upper limits of cloud forests, between 2900-3800 m (De la Riva 2005).

Interestingly, in recent times, a rare species of Gastrotheca has been seen and photographed in the Yungas of La Paz, near the type locality of $G$. coeruleomaculatus (see Pacheco, 2015). Also, a few juveniles from nearby locations are available in the CBF collection. Individuals have been described by Pacheco (2015) as having 3-4 $\mathrm{cm}$ in SVL, dorsal skin smooth, coloration varying between reddish-brown and grayish-brown, with green spots on dorsum and flanks; the venter and chest are covered by yellow and blue granules, and the ventral surfaces of thighs are bright orange (Fig. 7). The species has been found in rocky environments on steep slopes between 2336-2598 m elevation (Pacheco 2015). Unfortunately, no adult specimens or tissues are available for the moment; thus, pertinent comparisons and the inclusion of samples of this species in ongoing studies based on molecular data will not be possible until appropriate material is collected. In the meantime, we consider that Gastrotheca coeruleomaculatus (Werner, 1899), is the name applicable to these largely lost and apparently rare Gastrotheca populations from Yungas of La Paz, which should deserve urgent study and protection.

\section{Acknowledgements}

We are grateful to James Aparicio (CBF), José M. Padial and Stephen Rogers (CMNH), Carlos Udiales (EBD), Lucindo Gonzáles (MNK) and Marta Calvo (MNCN) for the loan of specimens. Cristina Paradela (MNCN), from the CT-Scan service of the MNCN, was extremely kind and helpful, striving to get the work done even during the difficult times imposed by the restrictions due to Covid-19. We thank Mauricio Pacheco for allowing us to reproduce his beautiful photos of Gastrotheca from Yungas of La Paz. This paper was financed by projects CGL2014-53523-P and PGC2018-097421-B-I00 (PI, Ignacio De la Riva) of the Spanish Ministry of Science and Innovation, partially with funds from the European Union.

\section{References}

Aguayo, R. (2009) Anfibios. In: Aguirre, L.F., Aguayo, R., Balderrama, J., Cortez, C. \& Tarifa, T. (Eds.), Libro Rojo de la Fauna Silvestre de Vertebrados de Bolivia. Ministerio de Medio Ambiente y Agua, La Paz, pp. 91-224.

Akmentins, M.S., Bonduri, Y.V., Contreras, P., Francisconi, L., Massabie, P.J. \& Santillán, J. (2014) Redescripción del canto de anuncio de Gastrotheca gracilis Laurent, 1969 (Anura: Hemiphractidae) y primer registro para el Parque Nacional Campo de Los Alisos, Tucumán, Argentina. Cuadernos de Herpetología, 28, 147-152.

Akmentins, M.S. \& Boullhesen, M. (2020) The advertisement call of Gastrotheca chrysosticta Laurent, 1976 (Anura: 
Hemiphractidae). Zootaxa, 4895 (2), 297-300.

https://doi.org/10.11646/zootaxa.4895.2.9

Blackburn, D.C. \& Duellman, W.E. (2013) Brazilian marsupial frogs are diphyletic (Anura: Hemiphractidae: Gastrotheca). Molecular Phylogenetics and Evolution, 68, 709-714. https://doi.org/10.1016/j.ympev.2013.04.021

Blotto, B.L., Lyra, M.L., Cardoso, M.C.S., Rodrigues, M.T., Dias I.R., Marciano-Jr., E., Dal Vechio, F., Orrico, V.G.D., Brandão, R.A., Lopes de Assis, C., Lantyer-Silva, A.S. F., Rutherford, M.G., Gagliardi-Urrutia, G., Solé, M., Baldo, D., Nunes, I., Cajadae, R., Torres, A., Grant, T., Jungfer, K.-H., da Silva, H.R., Haddad, C.F.B. \& Faivovich, J. (2021) The phylogeny of the Casque-headed Treefrogs (Hylidae: Hylinae: Lophyohylini). Cladistics, 37, 36-72. https://doi.org/10.1111/cla.12409

Boulenger, G.A. (1900) Reptilia and Batrachia (1899). Zoological Record, 36, 1-31.

Castroviejo-Fisher, S., Padial, J.M., De la Riva, I., Pombal Jr., J.P., Da Silva, H., Rojas-Runjaic, F.J.M., Medina-Méndez, E. \& Frost, D. (2015) Phylogenetic systematics of egg-brooding frogs (Anura: Hemiphractidae) and the evolution of direct development. Zootaxa, 4004 (1), 1-75.

https://doi.org/10.11646/zootaxa.4004.1.1

Cei, J.M. (1980) Amphibians of Argentina. Monitore Zoologico Italiano, New Series, Monograph 2, 1-609.

Clemente-Carvalho, R.B., Antoniazzi, M.M., Jared, C., Haddad, C.F., Alves, A.C., Rocha, H.S., Pereira, G.B., Oliveira, D.F., Lopes, R.T. \& dos Reis, S.F. (2009) Hyperossification in miniaturized toadlets of the genus Brachycephalus (Amphibia: Anura: Brachycephalidae): microscopic structure and macroscopic patterns of variation. Journal of Morphology, 270, $1285-1295$. https://doi.org/10.1002/jmor.10755

De la Riva, I. (1990) Lista preliminar comentada de los anfibios de Bolivia con datos sobre su distribución. Bollettino del Museo regionale di Scienze naturali, Torino, 8, 261-319.

De la Riva, I. (1992) Comentarios sobre el género Gastrotheca (Anura: Hylidae) en Bolivia y descripción de una nueva especie. Revista Española de Herpetología, 6, 15-22.

De la Riva, I. (2005) Bolivian frogs of the genus Telmatobius (Anura: Leptodactylidae): synopsis, taxonomic comments, and description of a new species. In: Lavilla, E.O. \& De la Riva, I. (Eds.), Studies on the Andean Frogs of the Genera Telmatobius and Batrachophrynus. Monografías de Herpetología 7. Asociación Herpetológica Española,Valencia, pp. 65-101.

De la Riva, I. (2020) Unexpected beta-diversity radiations in highland clades of Andean Terraranae frogs. In: Rull, V. \& Carnaval, A. (Eds.), Neotropical Diversification: Patterns and Processes. Fascinating Life Sciences, Springer Nature Switzerland AG, Cham, pp. 741-764. https://doi.org/10.1007/978-3-030-31167-4_27

De la Riva, I., Márquez, R. \& Bosch, J. (1995) Advertisement calls of eight Bolivian species of Hylids (Amphibia, Anura). Journal of Herpetology, 29, 113-118. https://doi.org/10.2307/1565094

De la Riva, I., Köhler, J., Lötters, S. \& Reichle, S. (2000) Ten years of research on Bolivian amphibians: updated checklist, distribution, taxonomic problems, literature, and iconography. Revista Española de Herpetología, 14, 19-164.

De la Riva, I. \& Aguayo, R. (2009) Gastrotheca lauzuricae In: Aguirre, L.F., Aguayo, R., Balderrama, J., Cortez, C. \& Tarifa, T. (Eds.), Libro Rojo de la Fauna Silvestre de Vertebrados de Bolivia. Ministerio de Medio Ambiente y Agua, La Paz, pp. $107-108$.

De la Riva, I. \& Aguayo, R. (2009) Gastrotheca splendens In: Aguirre, L.F., Aguayo, R., Balderrama, J., Cortez, C. \& Tarifa, T. (Eds.), Libro Rojo de la Fauna Silvestre de Vertebrados de Bolivia. Ministerio de Medio Ambiente y Agua, La Paz, pp. $125-126$.

De la Riva, I. \& Reichle, S. (2014) Diversity and conservation of the amphibians of Bolivia. Herpetological Monographs, 28, 46-65. https://doi.org/10.1655/HERPMONOGRAPHS-D-13-00009

Del Pino, E.M. \& Escobar, B. (1981) Embryonic stages of Gastrotheca riobambae (Fowler) during maternal incubation and comparison of development with other marsupial frogs. Journal of Morphology, 167, 277-295. https://doi.org/10.1002/jmor.1051670303

Du Plessis, A., Broeckhoven, C., Guelpa, A. \& Le Roux, S. G. (2017) Laboratory x-ray micro-computed tomography: a user guideline for biological samples. GigaScience, 6, 1-11. https://doi.org/10.1093/gigascience/gix027

Duellman, W.E. (1970) The Hylid Frogs of Middle America. Monograph of the Museum of Natural History, the University of Kansas, 1, 1-753.

Duellman, W.E. \& Fritts, T. (1972) A taxonomic review of the Southern Andean marsupial frogs (Hylidae: Gastrotheca). Occasional Papers of the Museum of Natural History, the University of Kansas, 9, 1-37. https://doi.org/10.5962/bhl.title.2835

Duellman, W.E. (1977) Liste der rezenten Amphibien und Reptilien: Hylidae, Centrolenidae, Pseudidae. Das Tierreich, 95, $1-225$. https://doi.org/10.5962/bhl.part.15140

Duellman, W.E. \& Trueb, L. (1986) Biology of Amphibians. McGraw-Hill Book Company, New York, New York, 670 pp. 
https://doi.org/10.2307/1445022

Duellman, W.E. \& Lynch, J.D. (1988) Anuran Amphibians from the Cordillera de Cutucú, Ecuador. Proceedings of the Academy of Natural Sciences of Philadelphia, 140, 125-142.

https://www.jstor.org/stable/4064938

Duellman, W.E. \& De la Riva, I. (1999) Rediscovery and taxonomic status of Hyla splendens Schmidt, 1857 (Anura: Hylidae). Copeia, 1999, 197-199. https://doi.org/10.2307/1447402

Duellman, W.E. \& Köhler, J. (2005) New species of marsupial frog (Hylidae: Hemiphractinae: Gastrotheca) from the Yungas of Bolivia. Journal of Herpetology, 39, 91-100. https://doi.org/10.1670/0022-1511(2005)039[0091:NSOMFH]2.0.CO;2

Duellman, W.E., Catenazzi, A. \& Blackburn, D.C. (2011) A new species of marsupial frog (Anura: Hemiphractidae: Gastrotheca) from the Andes of southern Peru. Zootaxa, 3095, 1-14.

Duellman, W.E., Barley, A.J. \& Venegas, P.J. (2014) Cryptic species diversity in marsupial frogs (Anura: Hemiphractidae: Gastrotheca) in the Andes of northern Peru. Zootaxa, 3768 (2), 159-177. https://doi.org/10.11646/zootaxa.3768.2.4

Duellman, W.E. (2015) Marsupial Frogs: Gastrotheca and Allied Genera. JHU Press, Baltimore, Maryland, 408 pp.

Echevarría, L.Y., De la Riva, I., Venegas, P., Rojas-Runjaic, F., Dias, L.R. \& Castroviejo-Fisher, S. (2021) Total evidence and sensitivity phylogenetic analyses of egg-brooding frogs (Anura: Hemiphractidae). Cladistics, 37, 375-401. https://doi.org/10.1111/cla.12447

Frost, R. (2021) Amphibian species of the world: an online reference. Version 6.0. American Museum of Natural History, New York, New Yor,. Available from: http://research.amnh.org/herpetology/amphibia/index.html (accessed 13 September 2021)

Hayek, L.A.C., Heyer, W.R. \& Gascon, C. (2001) Frog Morphometrics: a cautionary tale. Alytes, 18, 153-17.

Herrel, A., De Grauw, E.D., \& Lemos-Espinal, J.A. (2001) Head shape and bite performance in xenosaurid lizards. Journal of Experimental Zoology, 290, 101-107. https://doi.org/10.1002/jez.1039

James, G., Witten, D., Hastie, T. \& Tibshirani, R. (2015) An Introduction to Statistical Learning with Applications in R. Springer, New York, New York, 426 pp.

Jared, C., Antoniazzi, M.M., Navas, C.A., Katchburian, E., Freymüller, E., Tambourgi, D.V. \& Rodrigues, M.T. (2005) Head co-ossification, phragmosis and defence in the casque-headed tree frog Corythomantis greeningi. Journal of Zoology, 265, $1-8$. https://doi.org/10.1017/S0952836904005953

Köhler, J. (2000) Amphibian diversity in Bolivia: a study with special reference to montane forest regions. Bonner zoologische Monographien, 48, 1-243.

Marcus, L.F. (1990) Traditional morphometrics. In: Rohlf, F.J. \& Bookstein, F.L. (Eds.), Proceedings of the Michigan Morphometrics Workshop. University of Michigan Museum of Zoology, Ann Arbor, Michigan, pp. 77-122.

Nieden, F. (1923) Anura I. Subordo Aglossa und Phaneroglossa, Sectio 1. Arcifera. Das Tierreich, 46, i-xxxii + 1-584. https://doi.org/10.1515/9783111434582-003

Ocampo, M., Aparicio, J., Pacheco, L.F., Roldán, A.I., Aguilar, M.S. \& Rocha, O. (2020) Evaluación del estado de conservación de la rana endémica Yunganastes bisignatus (Anura, Craugastoridae) en Bolivia. Ecología en Bolivia, 55, $26-35$.

Pacheco, M. (2015) Guía fotográfica de los anfibios de la región de los Yungas-Bolivia. https://diversidadentrependientes. wordpress.com (accessed 19 October 2021)

Paluh, D.J., Stanley, E.L. \& Blackburn, D.C. (2020) Evolution of hyperossification expands skull diversity in frogs. Proceedings of the National Academy of Sciences, 117, 8554-8562. https://doi.org/10.1073/pnas.2000872117

R Core Team (2020). R: A language and environment for statistical computing. R Foundation for Statistical Computing, Vienna. Available from: https://www.R-project.org/ (accessed 5 May 2020)

Schmidt, O. (1857) Diagnosen neuer Frösche des zoologischen Cabinets zu Krakau. Sitzungsberichte der Kaiserlichen Akademie der Wissenschaften. Mathematisch-Naturwissenschaftliche Classe, 24, 10-15.

Seibert, E.A., Lillywhite, H.B. \& Wassersug, R.J. (1974) Cranial coossification in frogs: relationship to rate of evaporative water loss. Physiological Zoology, 47, 261-265. https://doi.org/10.1086/physzool.47.4.30152529

Trueb, L. (1970) Evolutionary relationships of casque-headed tree frogs with co-ossified skulls (family Hylidae). University of Kansas publications, Museum of Natural History, 18, 547-716. https://doi.org/10.5962/bhl.part.19992

Trueb, L. (1973) Bones, frogs, and evolution. In: Vial, J.L. (Ed.), Evolutionary Biology of the Anurans: Contemporary Research on Major Problems. University of Missouri Press, Columbia, Missouri, pp. 65-132.

Trueb, L. \& Duellman, W.E. (1978) An extraordinary new casque-headed marsupial frog (Hylidae: Gastrotheca). Copeia, 1978, 498-503. https://doi.org/10.2307/1443617

Vellard, J. (1957) Estudios sobre batracios andinos. IV. El género Gastrotheca. Memorias del Museo de Historia Natural “Javier 
Prado", 5, 1-47.

Venables, W.N. \& Ripley, B.D. (2002) Modern Applied Statistics with S. Springer, New York, New York, 138 pp. https://doi.org/10.1007/978-0-387-21706-2_5

Werner, F. (1899) Beschreibung neuer Reptilien und Batrachier. Zoologischer Anzeiger, 22, 479-484.

Wiens, J.J., Kuczynski, C.A., Duellman, W.E. \& Reeder, T.W. (2007) Loss and re-evolution of complex life cycles in marsupial frogs: Does ancestral trait reconstruction mislead? Evolution, 61, 1886-1899. https://doi.org/10.1111/j.1558-5646.2007.00159.x

Wild, E.R. (1997) Description of the adult skeleton and developmental osteology of the hyperossified horned frog, Ceratophrys cornuta (Anura: Leptodactylidae). Journal of Morphology, 232, 169-206.

https://doi.org/10.1002/(SICI)1097-4687(199705)232:2\%3C169::AID-JMOR4\%3E3.0.CO;2-5 


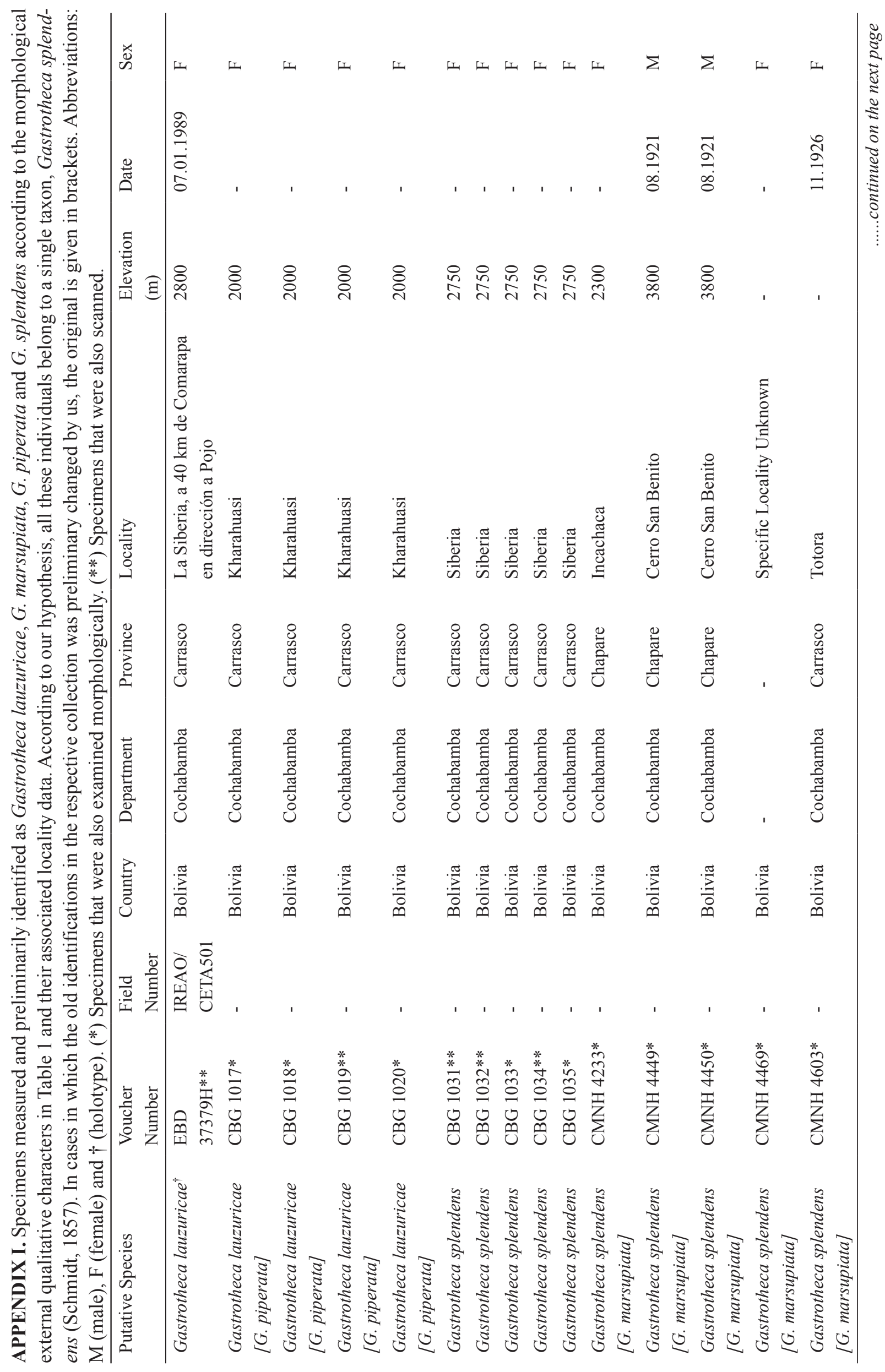




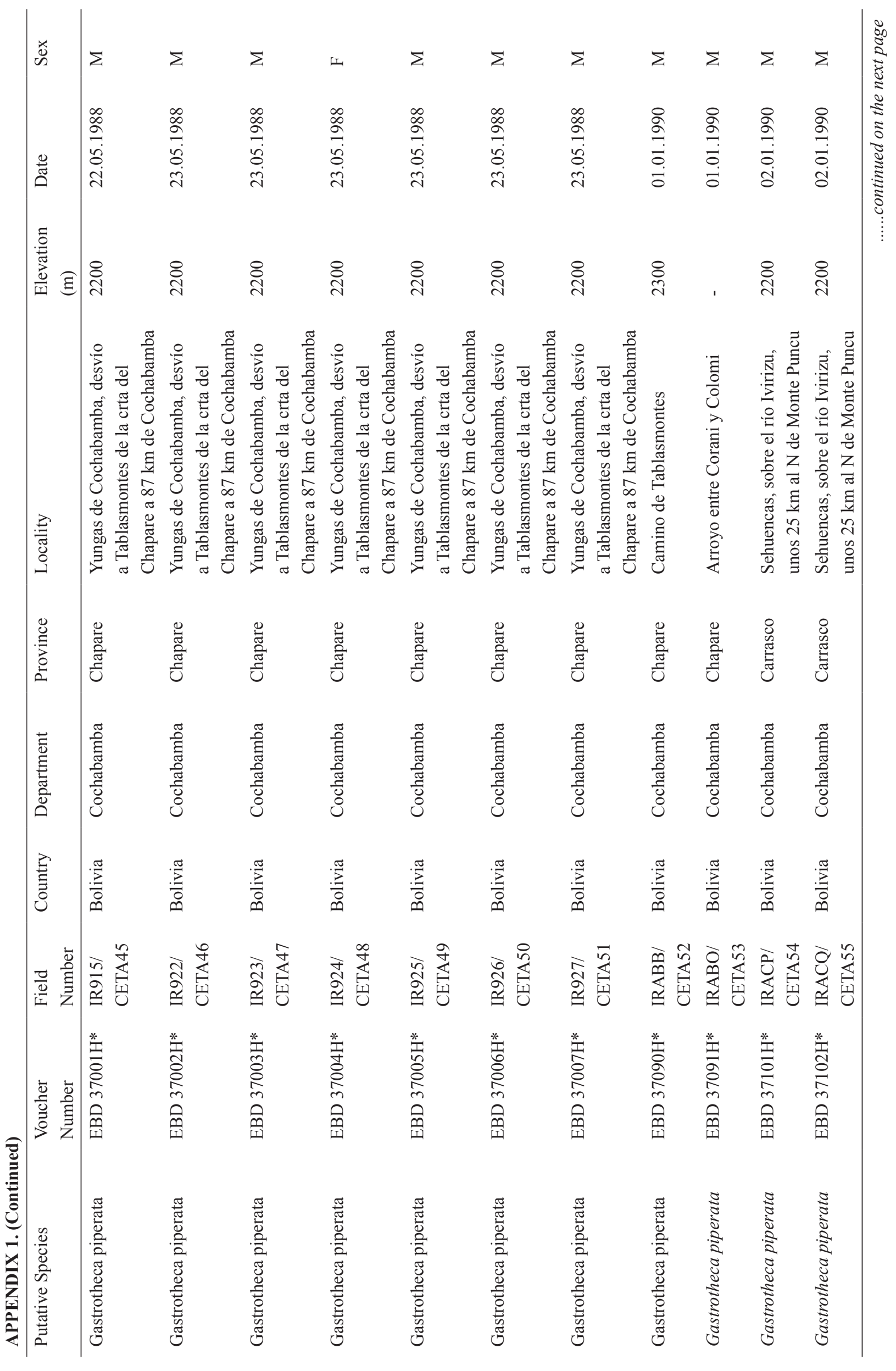




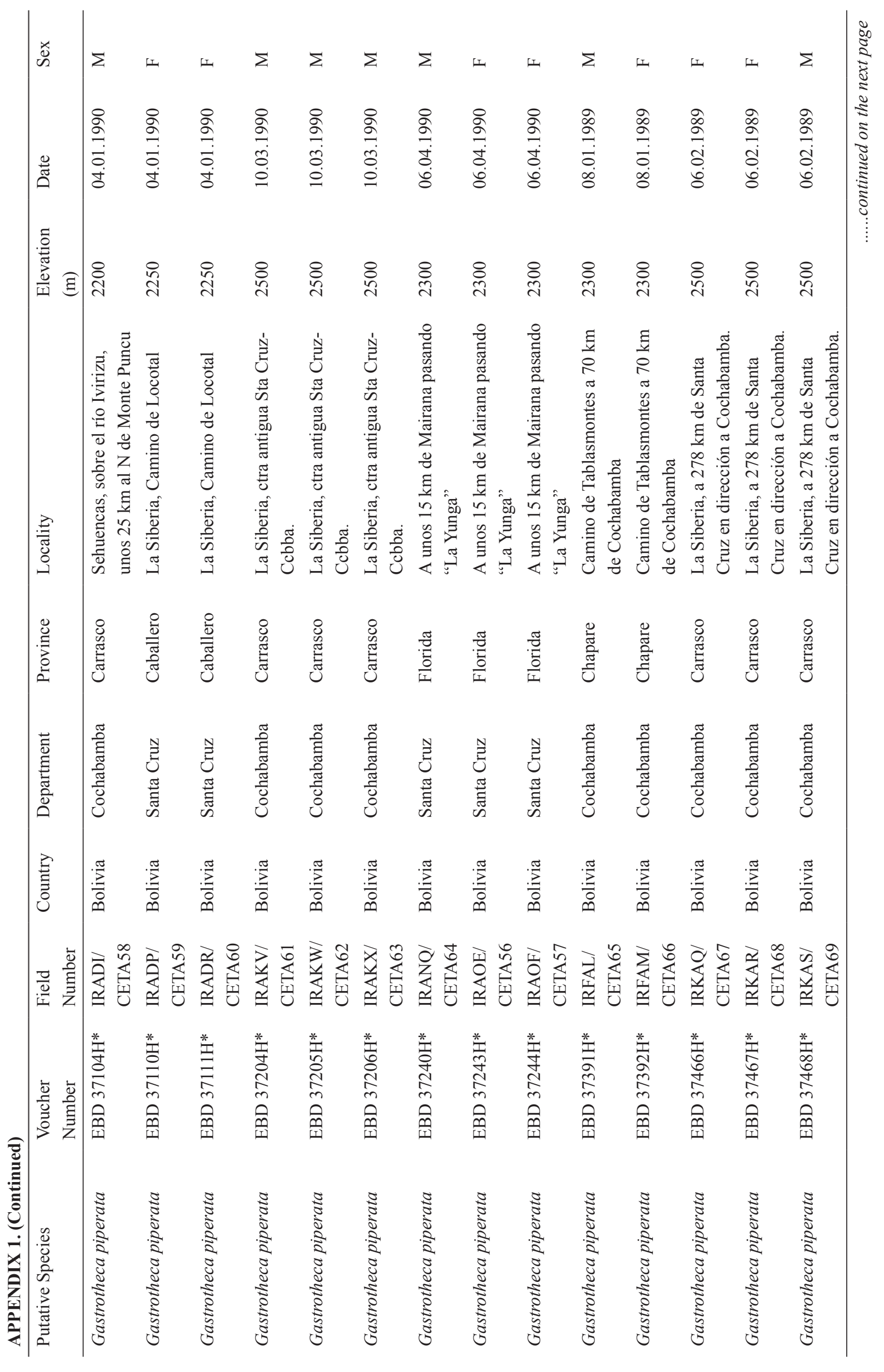




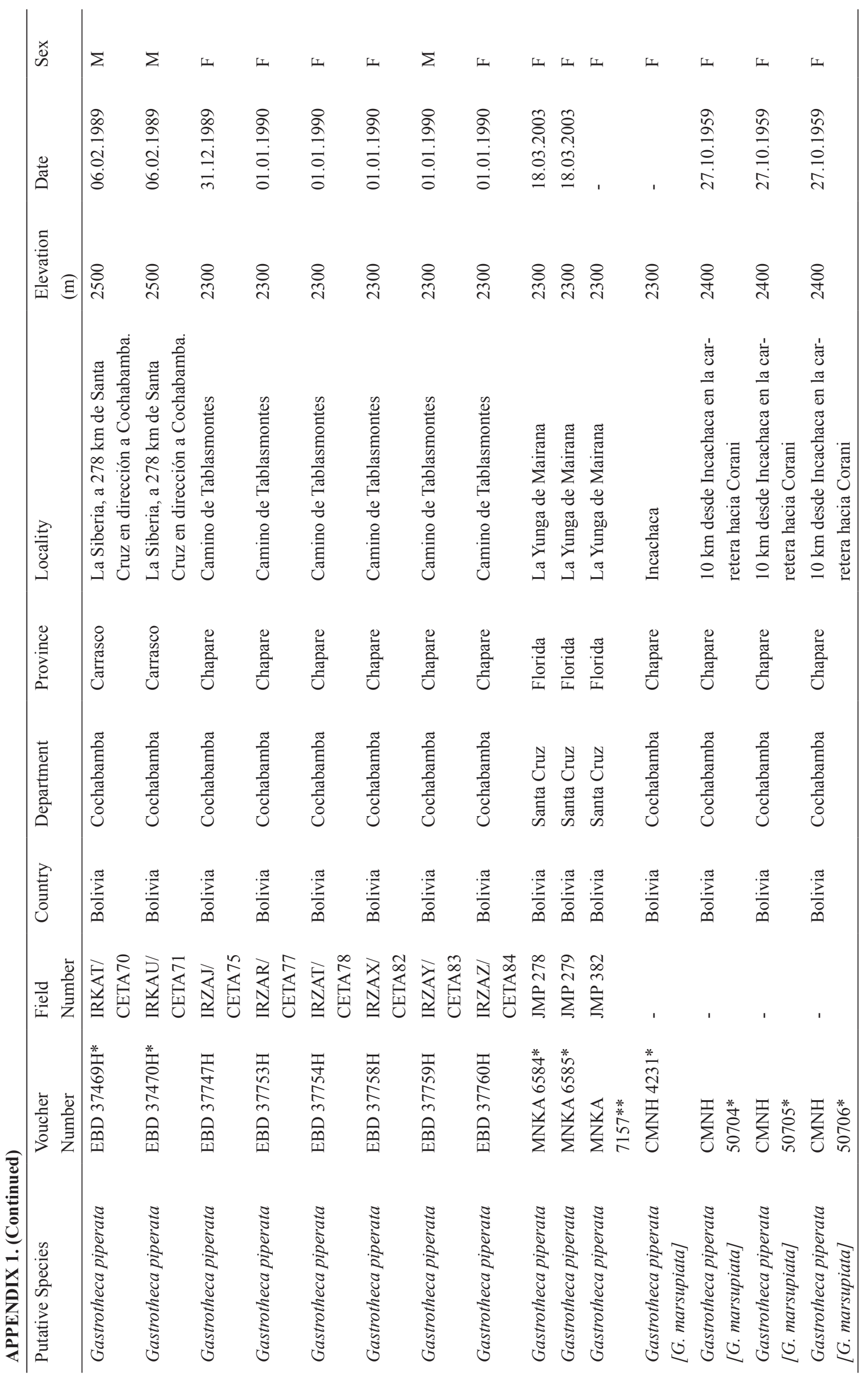

